\title{
Overview of NIST Research on Seismic Performance of Moment Resisting Precast Concrete Beam-Column Joints Containing Post-Tensioning
}

Building and Fire Research Laboratory Gaithersburg, Maryland 20899

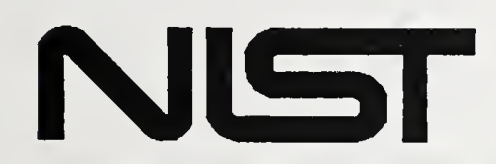

United States Department of Commerce Technology Administration

National Institute of Standards and Technology 


\section{Overview of NIST Research on Seismic Performance of Moment Resisting Precast Concrete Beam-Column Joints Containing Post-Tensioning}

Geraldine S. Cheok

William C. Stone

\section{August 1993}

Building and Fire Research Laboratory

National Institute of Standards and Technology

Gaithersburg, MD 20899

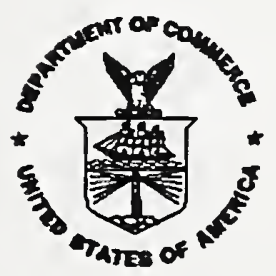

U.S. Department of Commerce

Ronald H. Brown, Secretary

Technology Administration

Mary L. Good, Under Secretary for Technology

National Institute of Standards and Technology

Arati Prabhakar, Director 

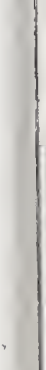


\begin{abstract}
The experimental test program being conducted at the National Institute of Standards and Technology on $1 / 3$-scale model precast concrete beam-to-column connections is summarized. The objective of the test program is to develop guidelines for an economical precast beamto-column connection for regions of high seismicity. The basic concept of the study is the use of post-tensioning for connecting the members. The monolithic test specimens were interior moment resisting connections designed using the Uniform Building Code [ICBO, 1985 and 1988] criteria for seismic Zones 2 and 4 as guidelines. The designs of the precast specimens were based on the monolithic design. To date, seventeen specimens have been tested. Variables in the study include location of the post-tensioning steel, the use of posttensioning bars versus prestressing strands, fully bonded versus partially bonded strands, and the combination of low strength steel and post-tensioning. Specimens were subjected to reversed cyclic loading according to a prescribed displacement history. Comparisons were made between the behavior of precast specimens and monolithic specimens. The comparisons were based on connection strength, connection ductility, and energy dissipation characteristics.
\end{abstract}




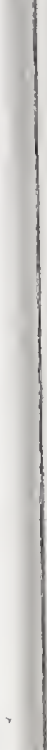




\section{CONTENTS}

Page

ABSTRACT $\ldots \ldots \ldots \ldots \ldots \ldots \ldots \ldots \ldots \ldots \ldots \ldots \ldots \ldots \ldots \ldots \ldots \ldots \ldots$ iii

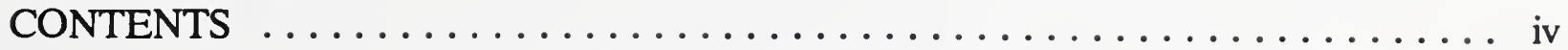

1.0 INTRODUCTION $\ldots \ldots \ldots \ldots \ldots \ldots \ldots \ldots \ldots \ldots \ldots \ldots \ldots \ldots \ldots \ldots \ldots \ldots$

2.0 TEST PROCEDURE AND SPECIMEN DETAILS $\ldots \ldots \ldots \ldots \ldots \ldots \ldots$

3.0 SUMMARY OF TEST RESULTS $\ldots \ldots \ldots \ldots \ldots \ldots \ldots \ldots \ldots \ldots$

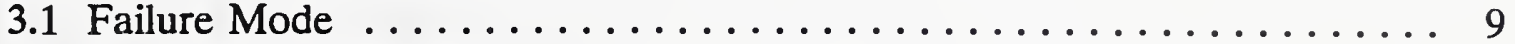

3.2 Displacement Ductility . . . . . . . . . . . . . . . . 9

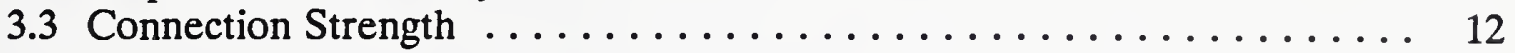

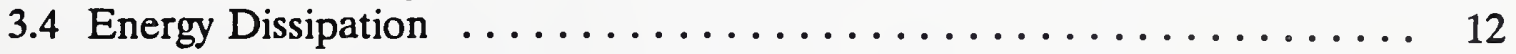

4.0 CONCLUSIONS AND FUTURE RESEARCH . . . . . . . . . . . . 17

4.1 Development of Code Criteria . . . . . . . . . . . . . . 18

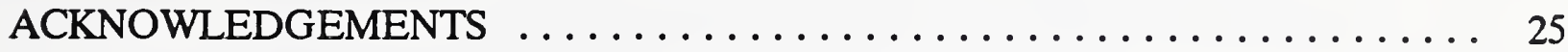

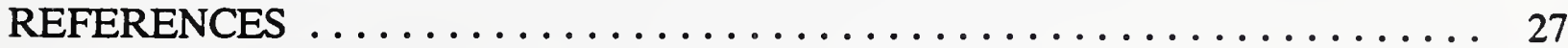

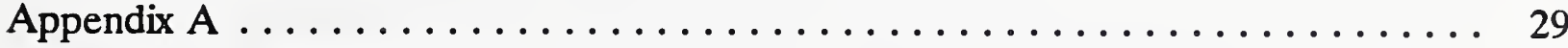

Appendix B: Organizational Chart ...................... 39 


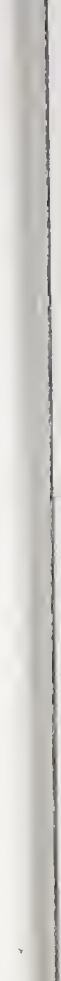




\section{LIST OF FIGURES}

PAGE

Figure 1. Boundary Conditions and Loading History. . . . . . . . . . 3

Figure 2. Beam Cross Sections for Monolithic Zones 2 and 4........... 5

Figure 3. Beam Cross Sections for Precast Specimens - Phases I - III. ......... 5

Figure 4. Beam Cross Sections for Phase IV Specimens I-P-Z4 and K-P-Z4. . . . . 6

Figure 5. Beam Cross Sections for Phase IV Specimen J-P-Z4. . . . . . . . . 6

Figure 6. Predicted Bilinear Elastic Behavior [Priestley and Tao 1993]. . . . . . . 7

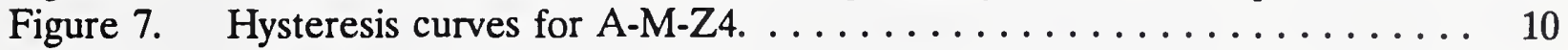

Figure 8. Hysteresis curves for A-P-Z4. $\ldots \ldots \ldots \ldots \ldots \ldots \ldots \ldots \ldots \ldots \ldots$

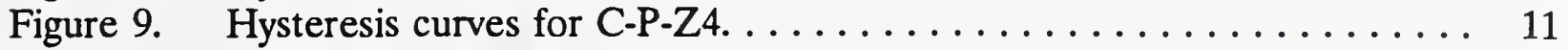

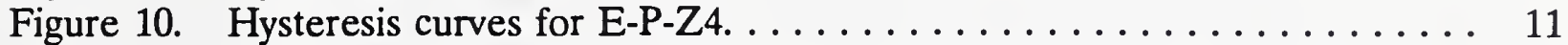

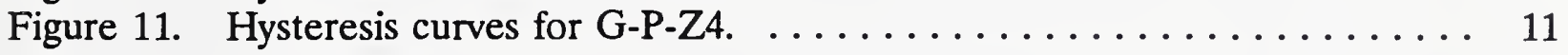

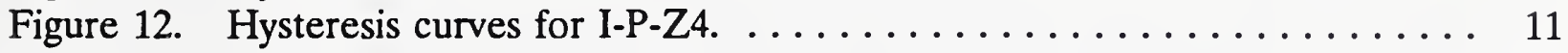

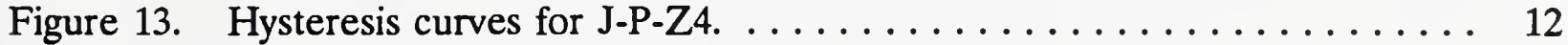

Figure 14. Hysteresis curves for K-P-Z4. . . . . . . . . . . . . . . 12

Figure 15. Comparison of the Normalized Cyclic Energy and Story Drift. . . . . . . 14

Figure 16. Experimental Hysteresis Curves for NIST Specimen A-P-Z4 . . . . . . 21

Figure 17. Predicted Hysteresis Curves Produced Using NIDENT 5.0 System Identification and IDARC 3.3 Inelastic Solution . . . . . . . . . . 22

Figure A1. Estimated acceptable damage indices, as functions of magnitude and distance, for bridge piers deemed moderately important to seismic lifelines ........................... 31

Figure A2. Estimated acceptable damage indices, as functions of magnitude and distance, for bridge piers deemed highly important to

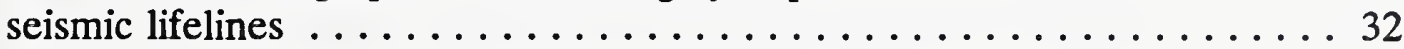

Figure A3. Proposed envelope for acceptable damage index, as a function of magnitude and distance, for bridge piers deemed moderately important to seismic lifelines . . . . . . . . . . . . . . . . . . 35

Figure A4. Proposed envelope for acceptable damage index, as a function of magnitude and distance, for bridge piers deemed highly important

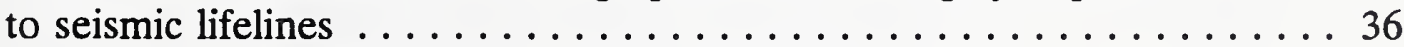




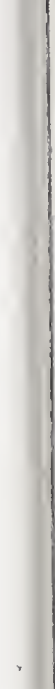




\subsection{INTRODUCTION}

A study of the behavior of $1 / 3$-scale model precast concrete interior beam-column connections subject to cyclic inelastic loading was initiated at the National Institute of Standards and Technology (NIST) in 1987. The objective of the ongoing experimental program is to develop guidelines for the design of an economical precast concrete beamcolumn connection for regions of high seismicity. The use of fully or partially bonded posttensioning in the connections is the major focus.

The test program consists of four phases. Phase I was an exploratory phase in which four monolithic specimens and two precast concrete specimens were tested. Test results of the monolithic specimens served as references for the precast concrete tests. The results from the precast tests were used to determine the viability of the connection details. Phase II of the program involved testing six (6) precast specimens. In an effort to improve the energy dissipation characteristics, the post-tensioning (PT) steel was moved closer to the beam center and the use of prestressing strands was compared with the use of post-tensioning bars. Because of stiffness degradation observed in the earlier precast specimens in the later stages of the tests, the use of partially bonded tendons was studied in Phase III. Two specimens were tested in this phase.

Phase IV, currently underway, examines the use of conventional low strength steel used in conjunction with PT steel as a means of improving the energy dissipation characteristics of the precast specimens. The premise for this concept is that the low strength steel will be used as an energy dissipator while the friction between the beam and column developed by the post-tensioning force will be used to provide the necessary shear resistance. Initially, concerns were raised that the friction force would be insufficient to resist the applied shear loads in addition to gravity loads. To address this concern, simulated gravity loads were applied to the beams for the Phase IV tests. The concept of the replaceability of both posttensioning and low strength steel is being investigated. The final segment of Phase IV will involve "production" testing in which the precast beams and columns will be fabricated by a precaster. The connections will then be assembled and tested at NIST. Some of the variables will include concrete strength, amount and type of low and high strength steel, and the construction joint material. Detailed results from Phases I, II and III may be found in References Cheok and Lew [1990, 1991, 1993] and Cheok, Stone, and Lew, [1992].

A steering committee was formed to provide technical guidance for Phases I-III. The members of this committee include Mr. Dan Jenny, Dr. Robert Englekirk, Dr. S. K. Ghosh, Mr. Paul Johal, and Dr. Nigel Priestley. Partial funding was made available from ConREF (Concrete Research and Education Foundation) for the Phase IV tests and an oversight committee was formed. Members of the oversight committee are listed in the organizational chart in Appendix B. 

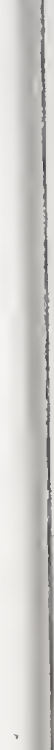


\subsection{TEST PROCEDURE AND SPECIMEN DETAILS}

The boundary conditions and basic loading history are shown in Fig. 1. Boundary conditions for the test specimens were as follows: pinned at the column bottom and roller supported at the column top and beam ends. Slight deviations from this basic load history were used in the actual tests: a third cycle at a particular displacement ductility was added if a significant loss in the peak lateral load occurred in the second cycle.

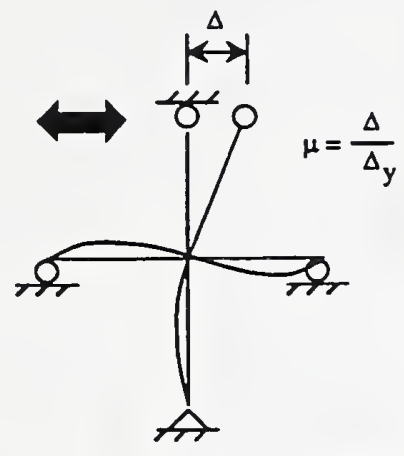

(a)

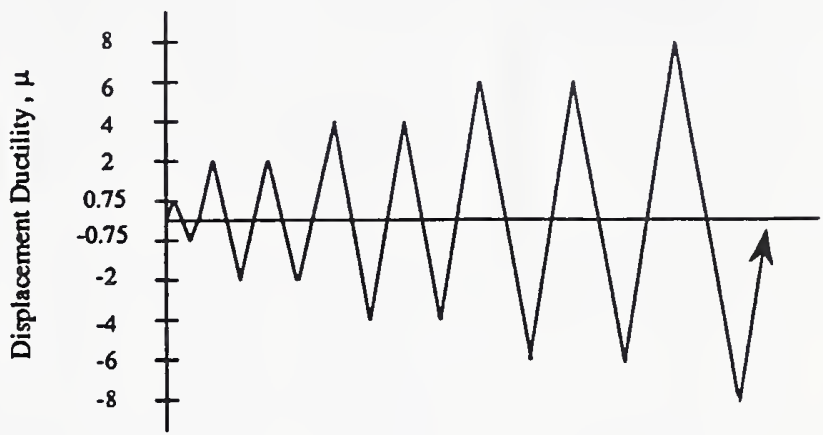

(b)

Figure 1. Boundary Conditions and Loading History.

The load history was similar to those used by other researchers [French, 1989] for cyclic testing and was chosen for the NIST tests so that comparisons could be made with these other tests. Failure was considered to have occurred when the lateral load during a cycle dropped below $80 \%$ of the maximum load that was achieved in the first cycle at $2 \Delta_{y}$. All columns were subjected to an axial load. However, the axial load imposed on the Phases I - III specimens was equal to $0.1 \mathrm{f}_{c} \mathrm{~A}_{\mathrm{g}}$ while the axial load for the Phase IV specimens was approximately equal to $0.4 \mathrm{f}_{\mathrm{c}} \mathrm{A}_{\mathrm{g}}$.

Concentrated loads simulating gravity loads on the beams were applied to the Phase IV specimens. A load of approximately $20 \mathrm{kN}$ was applied to each beam at approximately 89 $\mathrm{mm}$ from the column face. The load was equivalent to a uniform dead load of $5.3 \mathrm{kPa}$ and live load of $2.4 \mathrm{kPa}$. The loads on the beams were maintained constant throughout the tests.

A description of the specimens is given in Table 1. The details and dimensions for the beams are given in Figs. 2 - 5. Phase III specimens, G-P-Z4 and H-P-Z4, were identical to specimens E-P-Z4 and F-P-Z4 which were tested in Phase II. The only difference between the Phase III specimens and the Phase II specimens was that the tendons in the Phase III specimens were debonded through the column and $381 \mathrm{~mm}$ on either side of the column. The reason for using partially debonded tendons was because of the loss of stiffness in the Phases I and II precast specimens in the latter stages of the tests. This loss of stiffness was attributed to the development of inelastic strains in the tendons. Through the use of partially debonded tendons, a reduction of the tendon strains was expected and thereby, a 
bilinear elastic behavior was predicted as shown in Fig. 6 [Priestley and Tao 1993]. The initial axial beam prestress was $7 \mathrm{MPa}$ for all the precast specimens in Phases I-III.

Table 1. NIST Specimens ${ }^{\mathrm{a}}$.

\begin{tabular}{|c|c|c|c|c|c|c|c|c|c|}
\hline \multirow{2}{*}{$\begin{array}{l}\text { Test } \\
\text { Phase }\end{array}$} & \multirow{2}{*}{$\begin{array}{c}\text { Specimen } \\
\text { Names }\end{array}$} & \multirow{2}{*}{$\begin{array}{c}\text { Seismic } \\
\text { Zone }\end{array}$} & \multirow[t]{2}{*}{ Type $^{b}$} & \multicolumn{2}{|c|}{ PT Steel } & \multirow{2}{*}{$\begin{array}{c}\text { Bar dist. } \\
\text { from extreme } \\
\text { fiber }\end{array}$} & \multirow{2}{*}{$\begin{array}{l}\text { Length of } \\
\text { debonded } \\
\text { PT Steel }\end{array}$} & \multicolumn{2}{|c|}{ Mild Steel } \\
\hline & & & & Type $^{c}$ & Bond $^{d}$ & & & Area & Bond $d$ \\
\hline I & $\begin{array}{l}\text { A-M-Z2 } \\
\text { B-M-Z2 }\end{array}$ & 2 & $\mathbf{M}$ & - & - & $\cdots$ & - & $568 \mathrm{~mm}^{2}$ & F \\
\hline I & $\begin{array}{l}A-M-Z A \\
B-M-Z A\end{array}$ & 4 & $\mathbf{M}$ & $\cdots$ & -.. & $\cdots$ & -- & $613 \mathrm{~mm}^{2}$ & $F$ \\
\hline I & $\begin{array}{l}\text { A-P-ZA } \\
\text { B-P-ZA }\end{array}$ & 4 & $\mathbf{P}$ & B & $\mathrm{F}$ & $89 \mathrm{~mm}$ & $\cdots$ & $\cdots$ & $\cdots$ \\
\hline II & $\begin{array}{l}\text { A-P-Z2 } \\
\text { B-P-Z2 }\end{array}$ & 2 & $\mathbf{P}$ & $\mathbf{S}$ & $\mathbf{F}$ & $63 \mathrm{~mm}$ & $\ldots$ & -- & - \\
\hline II & $\begin{array}{l}\text { C-P-ZA } \\
\text { D-P-ZA }\end{array}$ & 4 & $\mathbf{P}$ & B & F & $135 \mathrm{~mm}$ & - & -.- & - \\
\hline II & $\begin{array}{l}\text { E-P-ZA } \\
\text { F-P-ZA }\end{array}$ & 4 & $\mathbf{P}$ & $\mathbf{S}$ & $\mathbf{F}$ & $102 \mathrm{~mm}$ & -- & - & $\ldots$ \\
\hline III & $\begin{array}{l}\text { G-P-ZA } \\
\text { H-P-ZA }\end{array}$ & 4 & $\mathbf{P}$ & $\mathbf{S}$ & $\mathbf{P}$ & $102 \mathrm{~mm}$ & $1219 \mathrm{~mm}$ & --- & - \\
\hline IV & $\begin{array}{c}\text { I-P-ZA } \\
\text { K-P-Z4 }\end{array}$ & 4 & $\mathbf{P}$ & $\mathbf{S}$ & $\mathbf{F}$ & $254 \mathrm{~mm}$ & -- & $142 \mathrm{~mm}^{2}$ & F \\
\hline IV & J-P-Z4 & 4 & $\mathbf{P}$ & B & $\mathrm{U}$ & $51 \mathrm{~mm}$ & $914 \mathrm{~mm}$ & $213 \mathrm{~mm}^{2}$ & $\mathrm{~F}$ \\
\hline IV & L-P-ZA & 4 & $\mathbf{P}$ & B & $\mathbf{U}$ & $40 \mathrm{~mm}$ & $914 \mathrm{~mm}$ & $186 \mathrm{~mm}^{2}$ & U \\
\hline
\end{tabular}

\footnotetext{
a Phase IV Parametric Specimens not included.

b $\quad \mathbf{M}=$ Monolithic; $\mathbf{P}=$ Precast

c $\quad \mathbf{B}=$ Post-tensioning bars; $\mathbf{S}=$ Prestressing strands

d $\quad \mathrm{F}=$ Fully grouted; $\mathrm{P}=$ Partially grouted; $\mathrm{U}=$ Unbonded
}

Note: $25.4 \mathrm{~mm}=1 \mathrm{in}$.

The details of the Phase IV specimens, Figs. 4 and 5, are different from those of the previous specimens because the designs were supplied by a precast contractor for a prototype building under consideration. The dimensions and details are typical for a moment resisting frame of an office structure. The beams in Phase IV have "dogbones" over and under expanded flanges measuring $51 \mathrm{~mm}$ (I-P-Z4 and K-P-Z4) and $68 \mathrm{~mm}$ (J-PZ4) high and $305 \mathrm{~mm}$ long (model dimensions) - which make the beams deeper at the column faces. The low strength steel in the Phase IV specimens extends from one end of the beam dogbone flanges through the column to the end of the second beam dogbone. Grade 40 reinforcing bars were chosen instead of Grade 60 bars for specimen I-P-Z4 for reasons of enhanced ductility. Specimen K-P-Z4 is identical to specimen I-P-Z4 with the only difference being the use of grade 60 reinforcing bars instead of grade 40 . Specimen K- 
P-Z4 was a retest of specimen I-P-Z4. This was because of premature failure of I-P-Z4 due to bond failure of the low strength steel as described later in this paper.
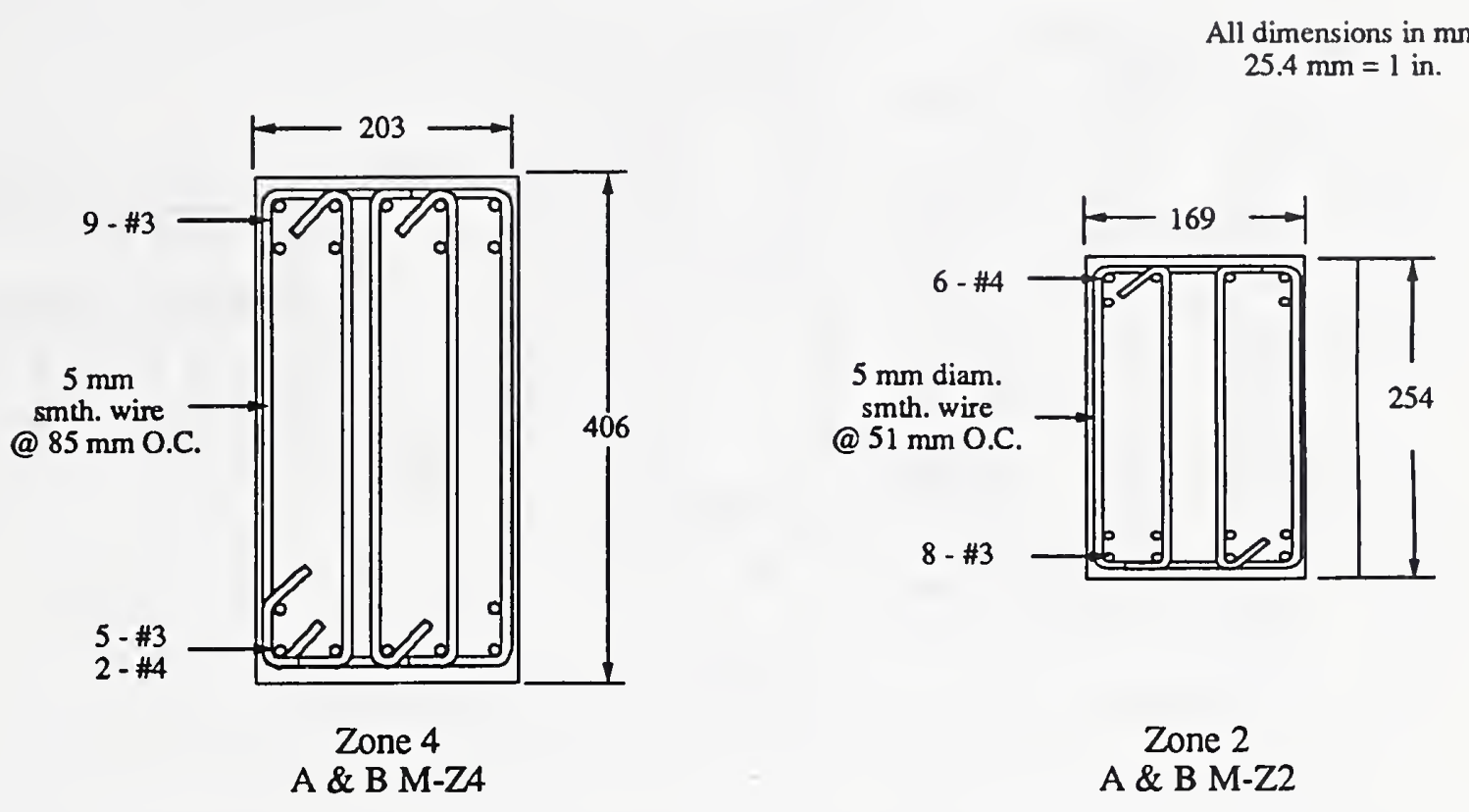

Figure 2. Beam Cross Sections for Monolithic Zones 2 and 4.

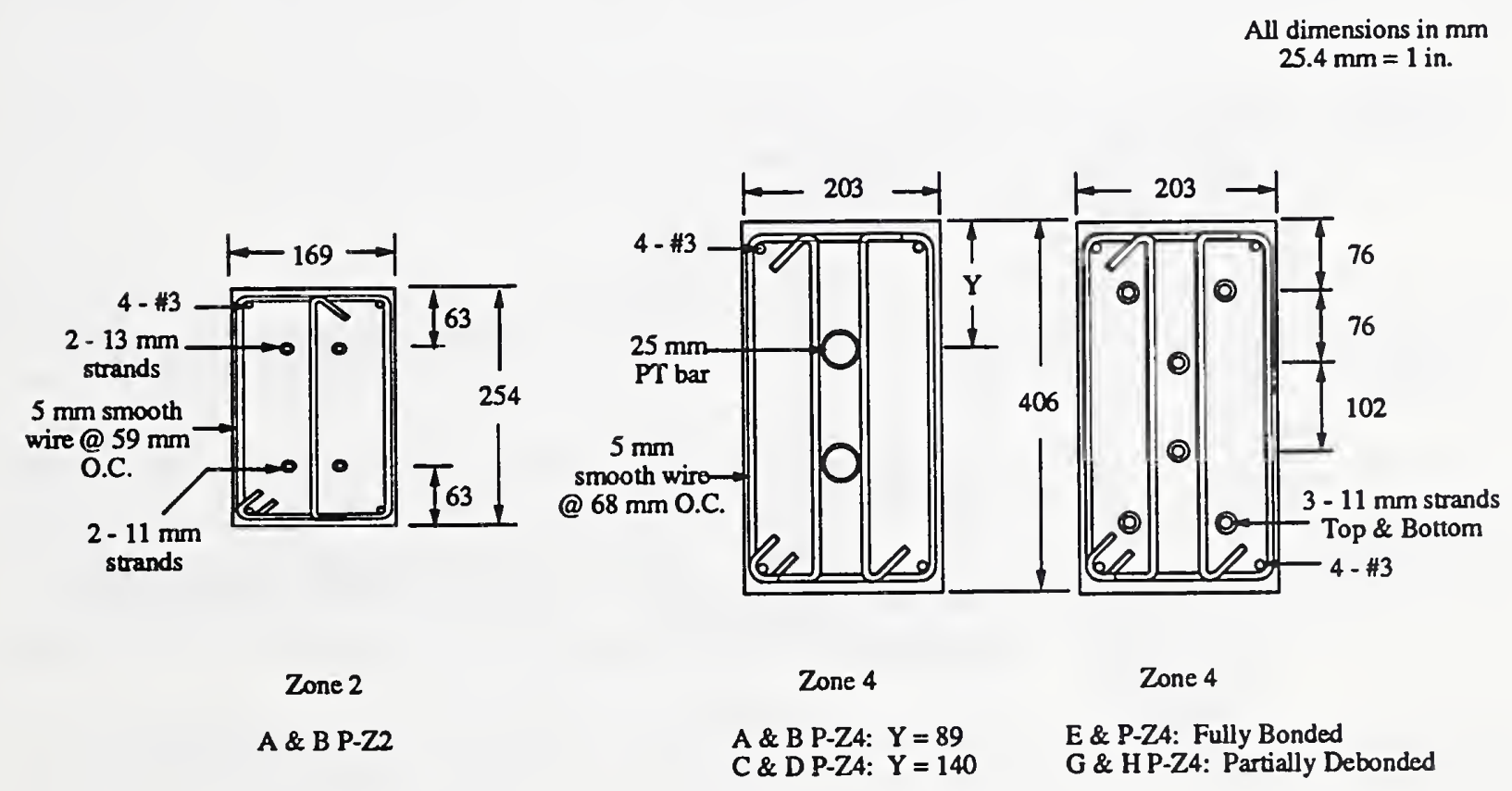

Figure 3. Beam Cross Sections for Precast Specimens - Phases I - III. 


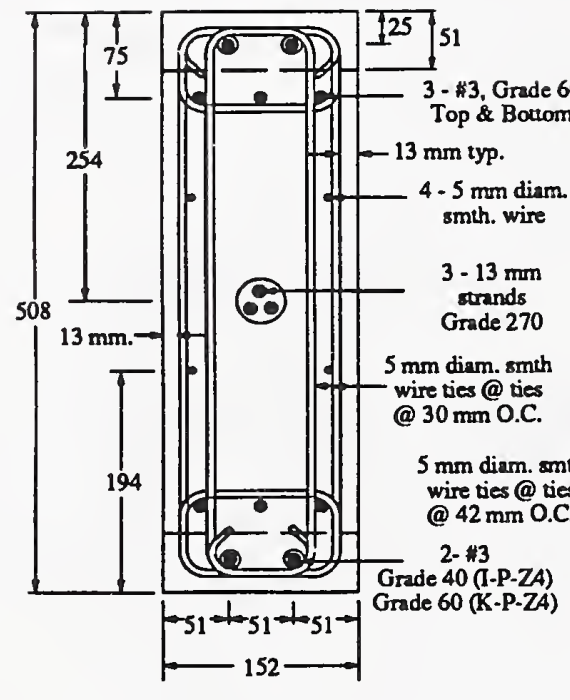

SECTION A-A

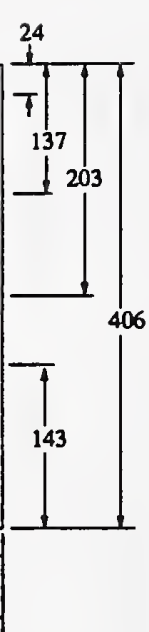

SECTION B-B

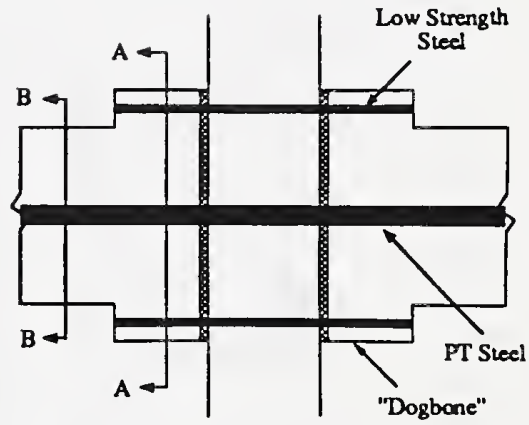

ELEVATION

Figure 4. Beam Cross Sections for Phase IV Specimens I-P-Z4 and K-P-Z4.

All dimensions in $\mathrm{mm}$ $25.4 \mathrm{~mm}=1 \mathrm{in}$.

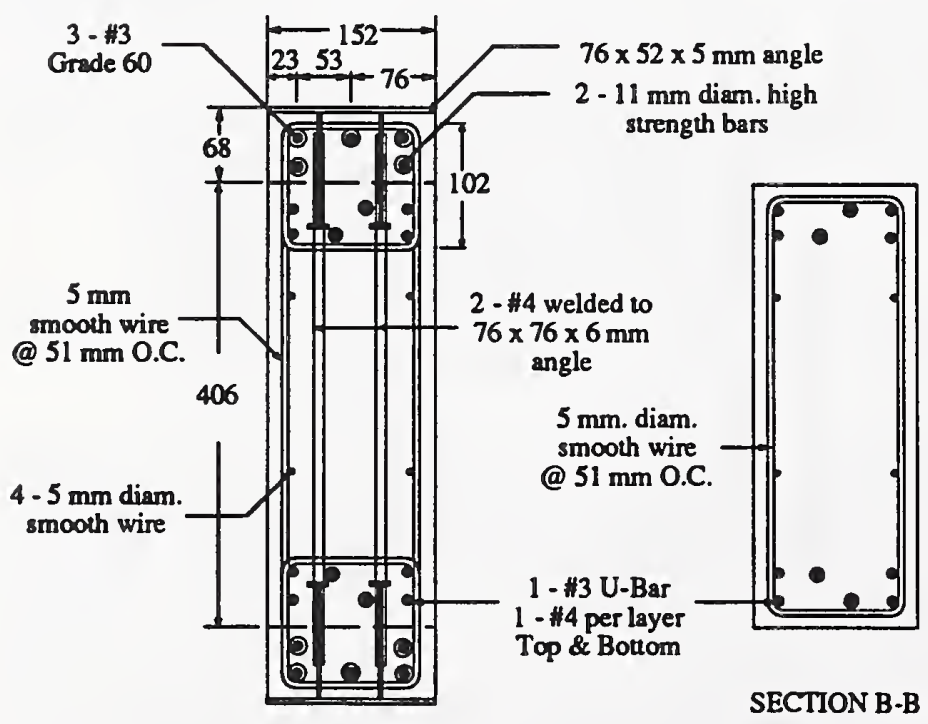

SECTION A-A

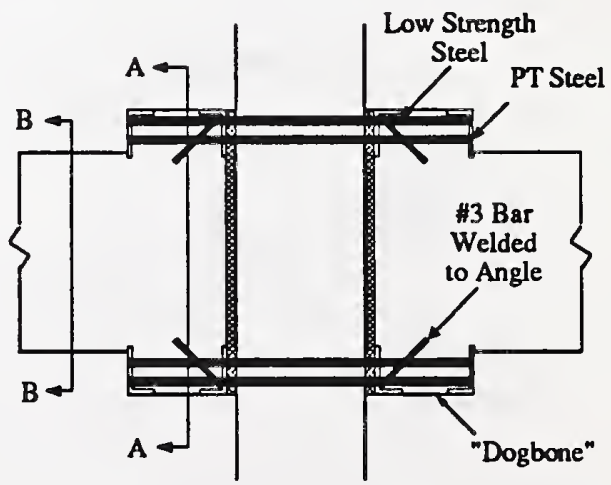

ELEVATION

Figure 5. Beam Cross Sections for Phase IV Specimen J-P-Z4. 


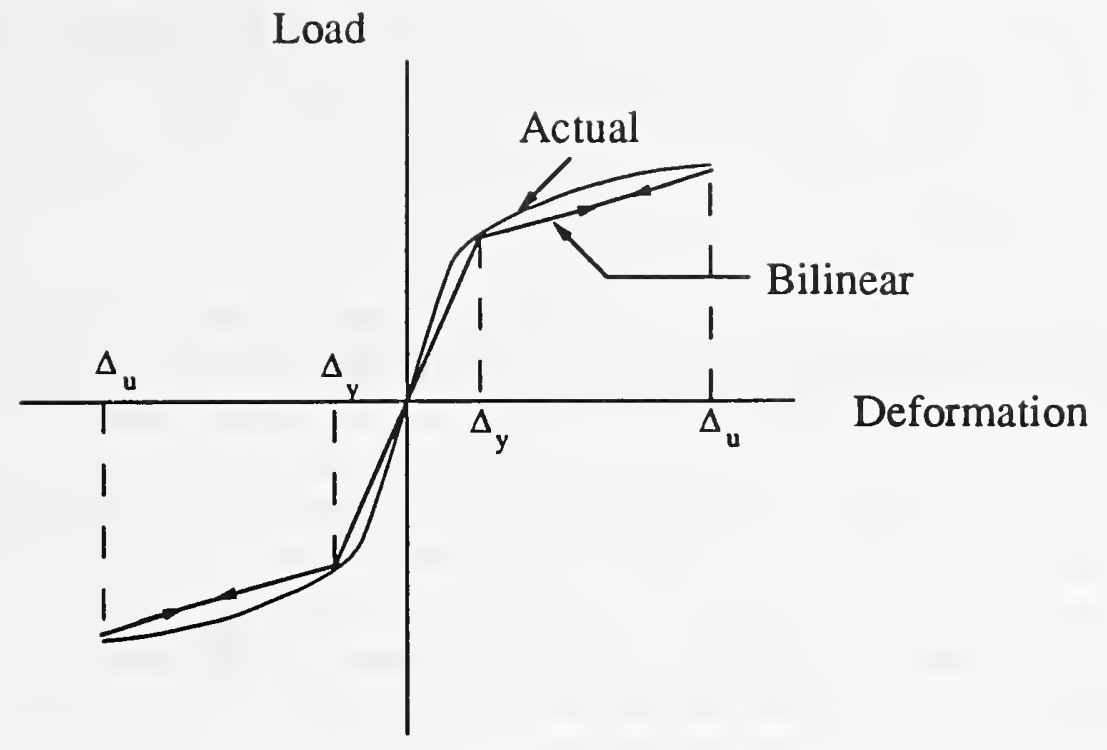

Figure 6. Predicted Bilinear Elastic Behavior [Priestley and Tao 1993].

The prestressing tendons in specimens I-P-Z4 and K-P-Z4 were located in the middle of the beam so that the tendons would experience low cyclic strains and would therefore not exhibit loss of stiffness due to yielding as observed in the earlier specimens. Specimen J-P-Z4 was post-tensioned through the use of high strength bars located in the dogbones. The high strength bars were ungrouted to delay the yielding of these bars. The low strength steel in this specimen consisted of \#3 grade 60 bars. The argument for using grade 60 instead of grade 40 is the greater availability of grade 60 bars and that the real yield stress of a grade $40 \mathrm{bar}$ is often closer to $414 \mathrm{MPa}$. The initial axial beam prestress was $5.0 \mathrm{MPa}$ for specimens I-P-Z4 and K-P-Z4 and 3.2 MPa for specimen J-P-Z4.

The foregoing descriptions show that the specimens in the four different phases were intended to perform in somewhat different ways and this should be kept in mind when the results are evaluated.

The monolithic specimens in Phase I were conventional reinforced concrete specimens containing only grade 60 reinforcing bars. Therefore, all the steel was intended to yield so that these specimens should generate the most hysteresis. However, the absence of posttensioning means that no clamping force exists across the interface and unloading of the specimen does not return the specimen to zero displacement.

The precast specimens in Phases I and II contained only post-tensioning. The posttensioning provided the necessary clamping force but only if the post-tensioning did not undergo extensive yield. Thus, with only one type of reinforcing, maintenance of the clamping force is possible at the expense of extensive energy dissipation and vice versa. Whereas the traditional objective is to maximize energy dissipation, some recent studies (Priestley and Tao, 1993) suggest that global displacements may in fact be controlled very 
nearly as well by the dissipation of only some energy provided that the other aspects of the behavior such as joint and member degradation are controlled. Some energy is dissipated by crushing of the concrete which is relatively undesirable because of the need for subsequent repairs and some by debonding. However, these sources do not dissipate much energy.

In the Phase III specimens, the post-tensioning steel was debonded through the column to reduce the amount of yielding in it. Doing so minimized the reduction in clamping force and the potential energy dissipation.

The Phase IV specimens were intended to take advantage of both clamping force action and energy dissipation. The post-tensioned steel was either unbonded or located in the center of the beam to avoid yielding and thereby maintain the clamping force. Energy dissipation was to be attained by yielding of the mild steel. The use of two different types of reinforcement allows the two objectives (maintenance of the clamping force and energy dissipation) to be met simultaneously.

The grout used in the construction joint between the precast beams and columns was fiber reinforced. The joint width in Phases I - III was $25 \mathrm{~mm}$ and the fibers were $19 \mathrm{~mm}$ straight steel fibers. The joint width in Phase IV was $6 \mathrm{~mm}$ and the fibers were $12 \mathrm{~mm}$ nylon fibers. Nylon fibers were used to avoid corrosion of the fibers. The strength of the nylon fiber reinforced grout was shown to be comparable to the grout with steel fibers, and the workability of the nylon reinforced grout was better. The surfaces of the beams and columns were roughened to an approximate amplitude of $6 \mathrm{~mm}$ in accordance with UBC [ICBO, 1985 \& 1988]. 


\subsection{SUMMARY OF TEST RESULTS}

\subsection{Failure Mode}

The monolithic Zone 4 specimens failed due to beam hinging and deterioration. All precast concrete specimen failure modes in Phases I - III were similar. Failure was characterized by yielding of the PT steel and beam crushing which resulted in an opening at the construction joint between the beam and column. Fine cracks developed in the column joint but otherwise, no significant damage occurred in this region. The width of the opening at the beam/column joint increased as the post-tensioning steel was placed closer to the beam centroid. The fiber reinforced construction joints for all the precast specimens held together well throughout the tests.

Unlike the monolithic Zone 2 specimens which failed predominantly in shear in the column joint region, the precast Zone 2 specimens did not experience severe joint distress. The failures of the monolithic Zone 2 specimens resulted from insufficient joint reinforcement in these specimens despite being designed in accordance with UBC requirements [ICBO, 1985]. However, the drift levels that these specimens were subjected are unlikely to occur in a region classified as Zone 2.

The Phase IV A precast specimens (J-P-Z4 and K-P-Z4) failed due to fracture of the low strength steel. Similar to the previous precast specimens, these specimens experienced beam crushing and joint openings between the beam and column.

Bond failure of the low strength steel was observed in specimen I-P-Z4. This failure occurred on the excursion to a story drift of $1.7 \%$ and occurred only in the beams and not in the column. The failure was attributed to the presence of strain gages and their coatings which eliminated approximately $40 \%$ of the available bond length. This was confirmed by subsequent pullout tests. Specimen K-P-Z4 was a retest of I-P-Z4.

\subsection{Displacement Ductility}

The ultimate displacement ductility and story drifts are given in Table 2. The low ultimate displacement ductility for precast specimen I-P-Z4 is due to premature bond failure of the low strength steel. In general, the precast Zone 4 specimens were more ductile than the monolithic specimens and as a result had higher story drifts at failure. The hysteresis plots for some of the Zone 4 specimens are given in Figs. 7 - 14. 
Table 2. Displacement Ductilities and Story Drifts.

\begin{tabular}{||c|c|c|}
\hline Specimen Name & $\begin{array}{c}\text { Ult. Displacement Ductility } \\
\left(\Delta / \Delta_{\nu}\right)\end{array}$ & $\begin{array}{c}\text { Story Drifts } \\
\text { at Failure (\%) }\end{array}$ \\
\hline A-M-Z2 \& B-M-Z2 & 6 & $4.1 / 4.3$ \\
A-P-Z2 \& B-P-Z2 & 4 & $2.6 / 2.5$ \\
A-M-ZA \& B-M-ZA & 6 & $3.0 / 3.4$ \\
A-P-ZA \& B-P-ZA & 10 & $3.1 / 3.4$ \\
C-P-ZA \& D-P-ZA & 12 & $4.8 / 4.9$ \\
E-P-ZA \& F-P-ZA & 12 & $5.2 / 5.0$ \\
G-P-ZA \& H-P-ZA & $14^{a}$ & $3.9^{a} / 3.6^{a}$ \\
I-P-ZA & 6 & 2.7 \\
J-P-ZA & 12 & 3.6 \\
K-P-ZA & 6 & 3.1 \\
\hline \hline
\end{tabular}

a These specimens were not tested to failure.

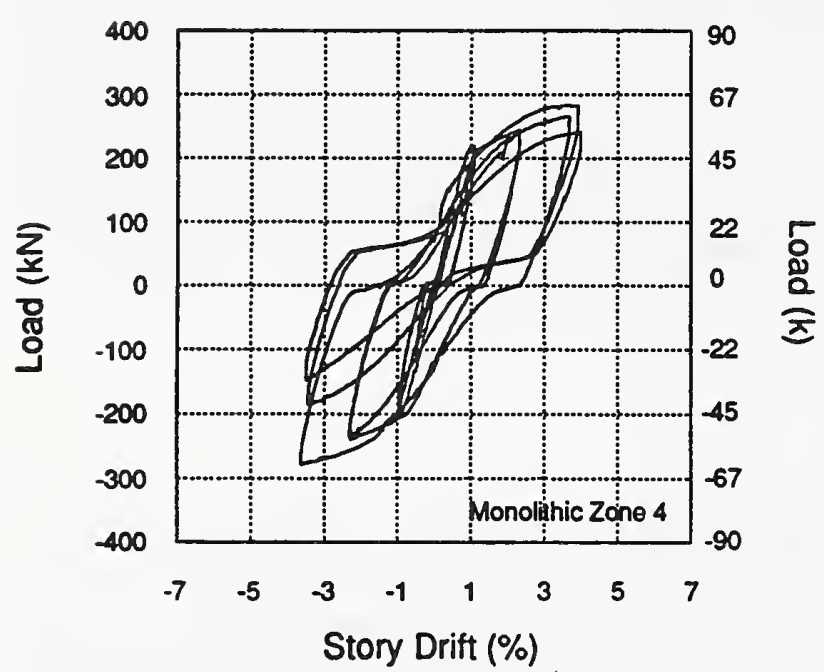

Figure 7. Hysteresis curves for A-M-Z4.

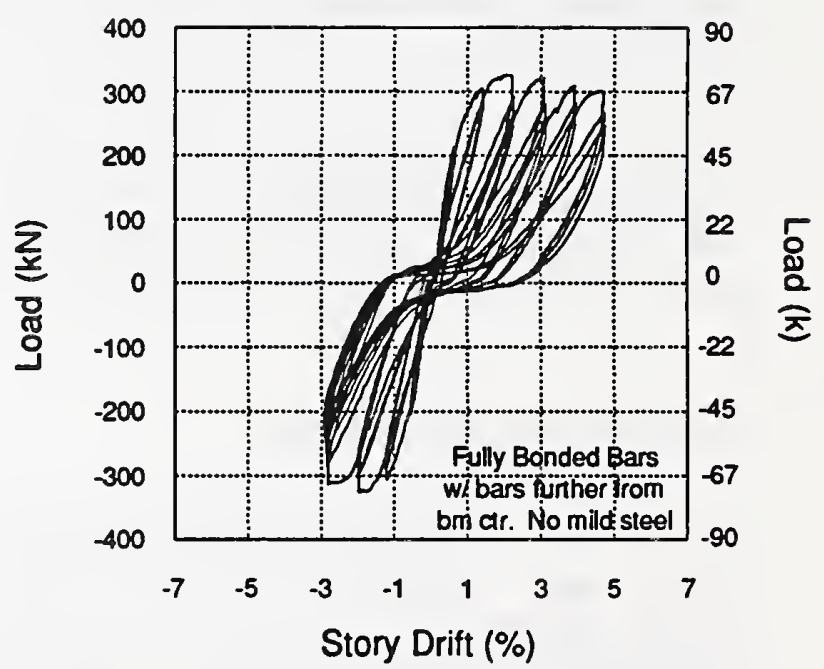

Figure 8. Hysteresis curves for A-P-Z4. 


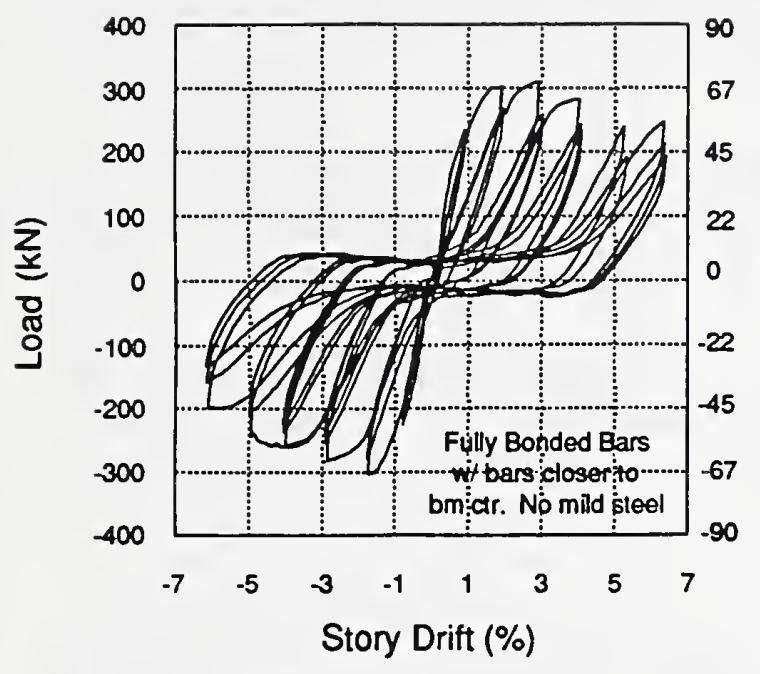

Figure 9. Hysteresis curves for C-P-Z4.

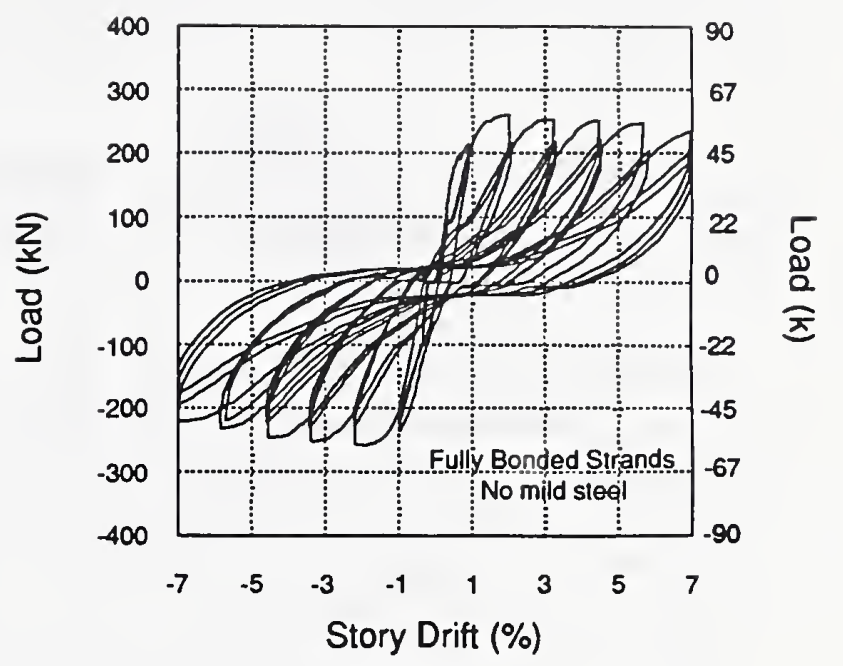

Figure 10. Hysteresis curves for E-P-Z4.

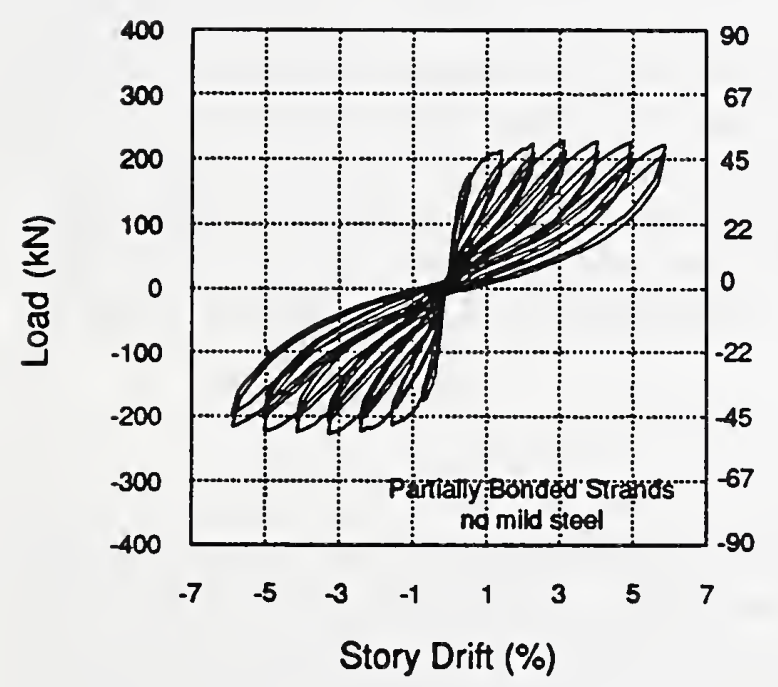

Figure 11. Hysteresis curves for G-P-Z4.

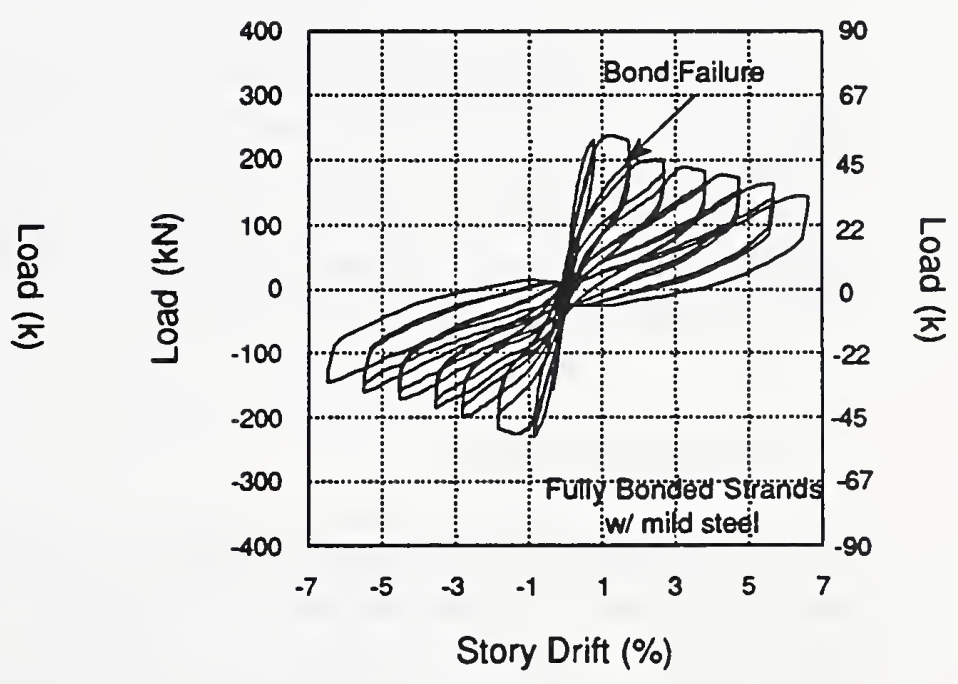

Figure 12. Hysteresis curves for I-P-Z4. 


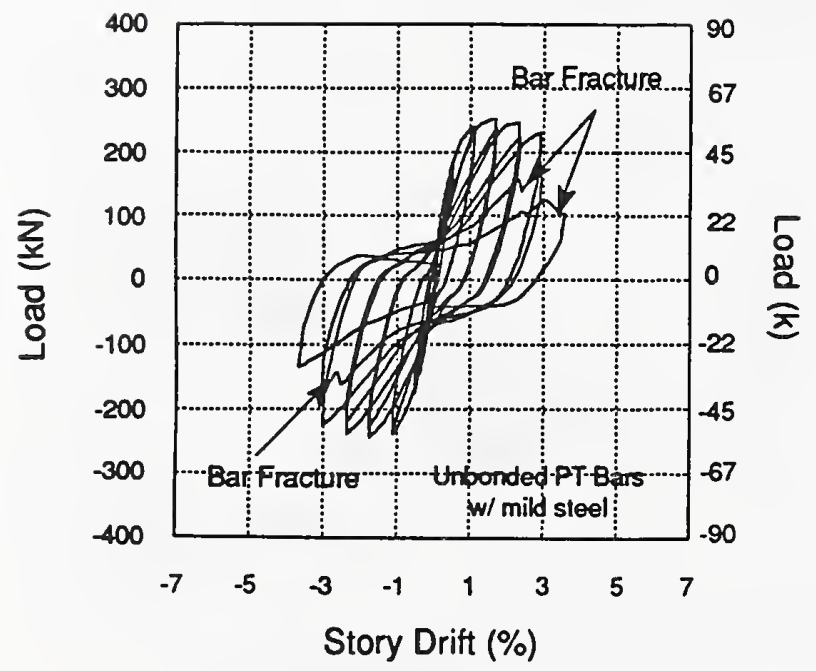

Figure 13. Hysteresis curves for J-P-Z4.

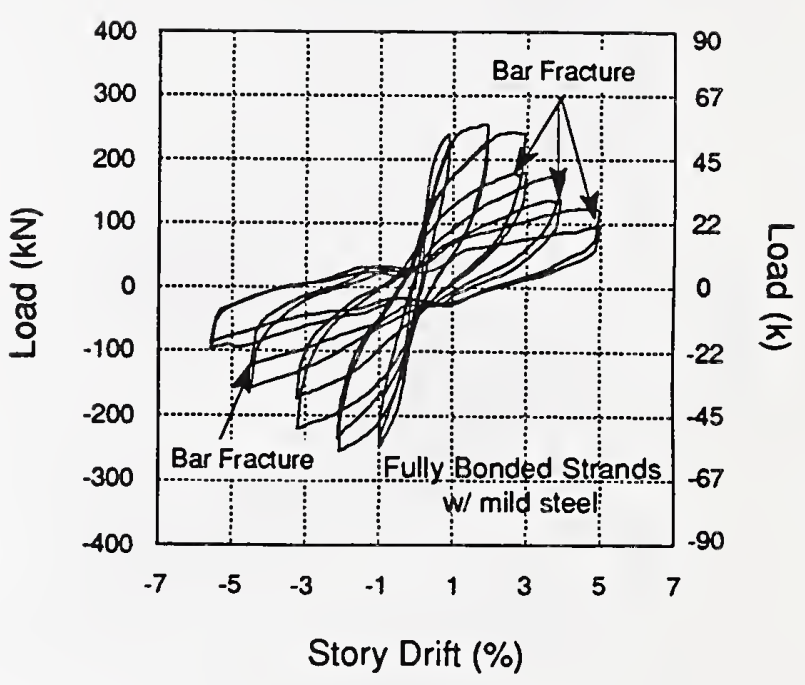

Figure 14. Hysteresis curves for K-P-Z4.

\subsection{Connection Strength}

The maximum experimental moments for all the precast specimens exceeded the predicted values. Except specimen I-P-Z4 where the failure mode was unanticipated, the precast specimens performed as well as the monolithic specimens in terms of connection strength. Moments for the monolithic specimens were calculated based on the actual yield stress of the steel with a factor of 1.25 applied to it to account for steel strain hardening, the 28-day concrete compressive strength and an ultimate concrete strain of 0.003 . The moments for the precast specimens were calculated using a Fortran program written for the PC. Steel strain hardening is accounted for in the program as the stress-strain curves used in the program for the given steel include values through bar fracture. The concrete compression force was computed based on a triangular stress distribution up to steel yield and on the Whitney stress block thereafter. Placement of the post-tensioning bars closer to the beam centroid does not appear to have a significant adverse effect on the connection strength.

\subsection{Energy Dissipation}

Due to the different yield displacements and concrete strengths for the specimens, it was felt that the most practical means to compare the energy dissipation was to plot the dimensionless cyclic energy dissipated against the story drift. The dimensionless quantity of cyclic energy dissipated was determined by dividing the energy dissipated per cycle $(\mathrm{kN}-\mathrm{m})$ by the maximum predicted moment $(\mathrm{kN}-\mathrm{m})$ and the story drift $(\%)$ for that cycle. 
As shown in Fig. 15 and from the hysteresis plots shown in Figs. 8 - 14, the cyclic energy dissipated by the precast specimens in Phases I - III was much less than that for the monolithic specimens. The specimen with fully bonded strands, E-P-Z4, performed as well specimens J-P-Z4 and K-P-Z4. However, specimen E-P-Z4 had approximately 50\% more PT steel than specimens J-P-Z4 and K-P-Z4. The cyclic energy dissipated is reduced by approximately $50 \%$ when partially bonded strands are used (G-P-Z4) instead of fully bonded strands (E-P-Z4).

The cyclic energy dissipated by the precast specimen I-P-Z4, the first specimen tested in Phase IV, was similar to that for the monolithic specimen until about $1 \%$ story drift when suspected debonding occurred.

The precast specimens in Phase IV (J-P-Z4 and K-P-Z4) matched the performance of the monolithic specimen up to approximately $2.0 \%$ story drift where fracture of the low strength steel occurred. Also, the drop in energy dissipated due to the lower amount of low strength steel (66\% of that used in J-P-Z4) used in specimen K-P-Z4 is not significant. It appears that locating the PT steel in the center of the beam improved the cyclic energy dissipation characteristics. Also, after fracture of the mild steel, the drop in cyclic energy dissipation was greater for specimen J-P-Z4 than for specimen K-P-Z4 likely due to a higher loss of the PT force in specimen J-P-Z4.

After fracture of the mild steel bars in specimen K-P-Z4, the normalized cyclic energy dissipation curve followed those of the other precast specimens with PT steel only (Fig. 15). The implications of this behavior are that even if seismic induced strains exceed the fracture strain for the energy dissipative steel, a fail-safe residual strength level will be provided by the PT steel.

Therefore, it appears that increased energy dissipation per cycle can be achieved by having fully bonded PT steel and mild steel. 


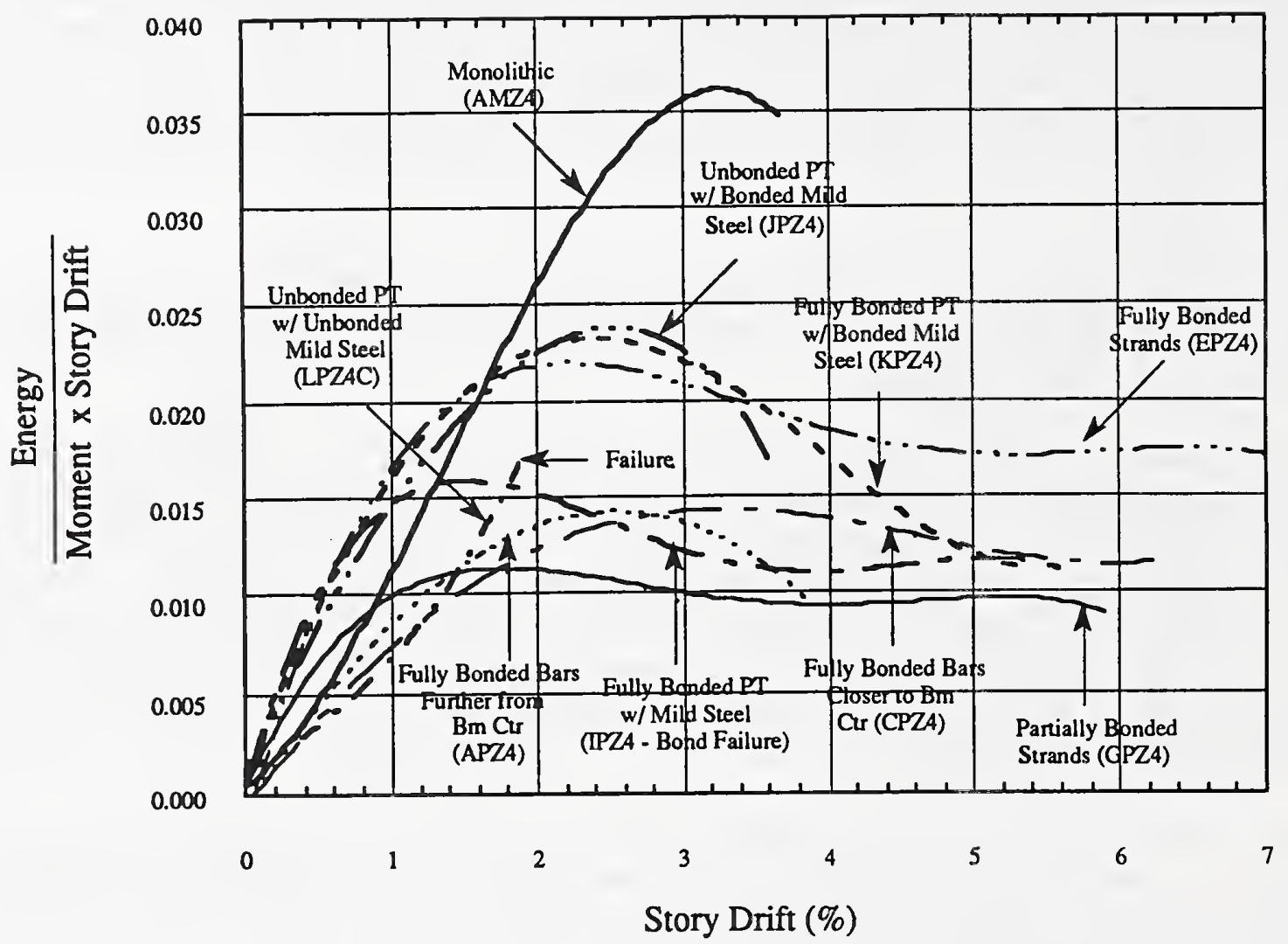

Figure 15. Comparison of the Normalized Cyclic Energy and Story Drift.

The cumulative energy dissipated to failure by precast Zone 4 specimens C-P-Z4 through F-P-Z4 was greater than the cumulative energy dissipated by the monolithic Zone 4 specimens. This is a result of the higher story drifts achieved by these precast specimens. The cumulative energy dissipated by the partially bonded precast Zone 4 specimens was equal to that for the monolithic Zone 4 specimens when the tests were terminated. The cumulative energy dissipation for these precast specimens would be even higher if the precast specimens were tested to failure.

Two points are worth discussing at this stage. First, the experimental data indicate that the envelope curve for the Phase III specimens can be approximated by a bilinear elastic relationship. However, a certain amount of damage was sustained by this joint detail during testing which lead to reduced stiffness during subsequent cycles to greater displacement ductilities. Significant spalling also occurred at the extreme compression fibers of the beams. Nonetheless, there was almost no reduction in strength at the conclusion of the tests $(\approx 6 \%$ story drift) which were stopped due to stroke limitations of the test facility.

The use of partially bonded tendons eliminates the slip zone (Figs. 8-10) at the zero displacement crossing that was characteristic of the Phases I and II specimens. However, 
the partially bonded precast specimens also dissipated significantly less energy than the fully bonded specimens - approximately 50\% less. The issue here is not strength capacity but one of drift limitation. In this sense the Phase III joints should prove viable, and robust, where site-specific time history analyses indicate that drift will not be a problem. Generally, one can expect this to be the case for high rise (long period) buildings founded on bedrock. Where hysteretic damping is to be relied upon (i.e. large energy dissipation per cycle) for drift limitation, then the Phase III detail should not be used.

Secondly, the results of the Phase IV specimens (J-P-Z4 and K-P-Z4) indicated comparable energy dissipation performance with monolithic joint details which is very promising. Also, displacement instrumentation indicated no vertical slip of the precast beams at the beam column joint throughout the test. This indicates that slip due to dead load shear is not a factor. However, for the sake of further verification, gravity loads will be applied to the remaining specimens in the Phase IV tests. 


\subsection{CONCLUSIONS AND FUTURE RESEARCH}

Post-tensioned precast concrete beam-column connections have been shown in this study to perform as well as or better than an equivalent monolithic specimen in terms of connection strength and ductility. Some of the configurations tested showed good emulation of the monolithic behavior in terms of energy dissipation. The precast connection does not require corbels or shear keys as the friction between the precast beams and column developed from the post-tensioning force was shown to be sufficient to resist the applied shear and gravity loads. From the results of the tests (Phases I - IV), improved energy dissipation per cycle was achieved by: a) including low strength steel through the joint region near the top and bottom of the beams; b) locating the PT steel closer to the beam centroid (if no mild steel is included); and c) having fully bonded PT steel (if no mild steel is included).

A third Phase IV exploratory connection is currently being constructed. This specimen is similar to specimen J-P-Z4, but it incorporates replaceable low strength and PT steel. The ability to repair a structure after an earthquake instead of condemning it is an attractive proposition. However, a joint with replaceable elements inherently involves more complex details which will increase its cost. The economic trade-offs of this approach will ultimately have to be weighed by the precast contractors and building owners. This specimen will be tested following a loading procedure based on story drift as this makes the comparisons between tests with different yield displacements and material properties much easier.

Due to steel congestion in the dogbone regions, simplification of the Phase IV designs will be necessary before the commencement of the production type testing. Phase IV "production" tests will investigate:

1) optimal amount of mild steel to achieve full emulation of monolithic joints

2) optimal amount of post-tensioning steel

3) effects of type of mild steel/ PT steel

4) methods for simplification of connection details

5) effects of higher concrete strength

Only four specimens will be tested in the production phase. This number of test specimens will clearly not allow all the variables listed above to be examined. However, the results from these and previous NIST specimens in addition to the results from PRESSS, as described below, will provide a basis from which the hysteretic model parameters will be determined.

A novel energy dissipator fabricated from deformed 304 stainless steel rods will be tested in Step 3 of the Phase IV production tests. This is predicated upon the observation that deviation from monolithic behavior for the NIST hybrid specimens initiated upon fracture of the mild steel energy dissipators. It is expected that the enhanced fatigue and strain capacity of a stainless dissipator would permit closer emulation of a monolithic joint to higher drift levels with the benefit of lower reinforcement ratios. 


\subsection{Development of Code Criteria}

Work at NIST, at universities and industry involved with the PRESSS program, and elsewhere have investigated (or are investigating) a number of precast moment resisting frame joint details that fall into the following seven categories:

1. Fully bonded PT strand, no mild steel

2. Fully bonded PT strand, bonded mild steel

(NIST)

3. Fully bonded PT bars, no mild steel

(NIST)

(NIST)

4. Partially debonded PT strand, no mild steel

(NIST)

5. Fully debonded PT strand, no mild steel

(U. C San Diego)

6. Unbonded PT bars, bonded mild steel

(NIST)

7. No PT, fully bonded mild steel

8. Unbonded PT bars, unbonded mild steel

(U. MN, U. TX, Austin)

(NIST)

From the data obtained thus far, there is clear evidence that precast moment resisting frames can be designed to meet the strength requirements of the UBC. For the range of specimens tested, the NIST and UCSD test programs have also shown that corbels may be eliminated from such designs and that friction developed at the interface between the beam and column via axial post-tensioning can be designed to handle gravity loads and seismic shear loads without any slip.

In almost all configurations tested, strength was maintained in the precast frames to story drifts levels of as much as $5 \%$ which is far in excess of the 1-1/2\% allowed. This indicates substantial reserve deformation capacity in the precast details which in many cases exceeds that of monolithic comparison tests.

In some designs tested, there was a significant slip zone in the hysteresis curves that developed due to yielding of the post-tensioning steel. This could, under certain inertial loading conditions, cause large lateral displacements and lead to unacceptable residual drift. Likewise, some designs exhibited nearly bi-linear elastic behavior. These latter two cases (slip-dominated and bi-linear elastic) require special design consideration from a drift limitation standpoint that would not be required of a joint detail matching or exceeding monolithic performance. However, as will be detailed below, it is felt that the use of more sophisticated design tools in these special cases will enable them to be safely used and permit a wide latitude of design freedom to the structural engineer.

From a design standpoint the following issues remain:

1. ISSUE \#1: What details allow a precast joint to match or exceed monolithic performance in terms of strength, energy dissipation, and drift capacity? Present work at NIST (see Fig. 15) has shown that hybrid joints (containing unbonded or bonded PT and mild steel) can achieve story drift limits beyond those allowed by the code. Other details are scheduled to be tested in NIST Phase IV B and in PRESSS Phase II. The mild steel in these tests serves as the energy dissipator while efforts must be taken at the same time to insure near elastic behavior in the PT steel to prevent slip-type behavior and to maintain the prestress necessary for 
resisting the applied shear force and gravity loads. Thus: 1) how much prestressed and non-prestressed steel is necessary to achieve satisfactory behavior? and 2) could other materials be used more efficiently to perform the function of the existing components (i.e. deformed stainless steel bars)?

Again, the objective of the precast design is not to emulate the behavior of a monolithic design. The damage in these frames is typically distributed in a plastic hinge zone about a beam depth long on either side of the columns. In the precast specimens, it is possible to keep the beams and columns essentially free from damage and to concentrate the inelastic action in the connection steel. This approach has the benefit of reducing, and in small to moderate earthquakes eliminating, the structural repair costs.

2. ISSUE \#2: What about new details not covered in the current research areas? In order to encourage innovation on the part of the precast industry, a simplified acceptance procedure needs to be established for joint details which do not fall within the bounds of the existing knowledge base. Since the design procedures for strength (moment capacity) and shear are straightforward, the only remaining issues are those of energy dissipation characteristics and story drift limitations.

Work at NIST has shown that joint details have very specific energy dissipative "signatures", as manifested in a plot of normalized cyclic dissipated energy versus drift (see, e.g., Fig. 15). Recognizing this, the following method for the determination and rating of new joint details is proposed:

A) Design the basic joint for moment and shear demand (both dead load and seismic load) using standard procedures.

B) Conduct a minimum of one, and preferably two tests, model or full-scale, of the proposed joint (interior beam column joint) using the drift-based cyclic loading procedure presently being employed by PRESSS [Priestley, 1992].

C) Plot the non-dimensionalized cyclic dissipated energy (as shown in Fig. 15) as a function of story drift for each cycle.

D) The precast joint is accepted if:

(1) For drifts of $2 \%$ or less, the experimental energy curve falls within the band of one standard deviation of the monolithic curve in Fig. 15 (or a similar, statistically derived curve based on experimental data for monolithic joint for other configurations).

(2) The joint can sustain a drift level of approximately $3 \%$ prior to the onset of strength deterioration.

Otherwise, it will be subject to the more rigorous analysis procedures described below. This is a somewhat rigid definition but it may be useful as the basis for committee debate and parametric sensitivity studies to determine how much deviation from the empirical monolithic behavior may still be considered acceptable. 
3. Issue \#3: What design procedures are to be used for joint details not matching or exceeding monolithic performance? The use of such a design for a specific region or site will initially require the use of time history analyses and a hysteretic model, calibrated using experimental data, to determine the expected drift. However, with sufficient parametric analyses, it should be possible to develop design models that will employ higher safety factors and simplified equivalent static design procedures.

Initial code development work for precast moment resisting frames under PRESSS [Hart, 1992] has identified three possible design procedures, distinguished by the level of required sophistication:

1. A simplified, equivalent static analysis which accounts for transient inelastic response through the use of conservative response modification factors in which allowable drift is severely restricted.

2. A design based on site specific response spectra involving essentially elastic analyses (with a limited amount of inelastic element response allowed) and story drift ratios limited to $1.5 \%$.

3. A transient, non-linear dynamic analysis using maximum credible site specific time histories with residual interstory drifts being limited to $0.5 \%$ following inelastic excursions.

Commensurate with the more sophisticated design procedures is a greater degree of design freedom. What is lacking at this stage is specific guidance to bridge the gap between the experimental data that exist (and is being expanded in PRESSS Phase II and NIST Phase IV B) on precast moment-resisting beam column joints and the design approaches described above. Before a time history analysis can yield valid design results, two critical components remain to be developed:

1. Hysteretic models must demonstrate a robustness to capture the seismic behavior of precast joints. System identification must then be carried out to characterize hysteretic parameter coefficients, using the available test database. There are several possible analytical platforms which might be utilized (e.g., IDARC, DRAIN-2DX) for this operation, but the hysteretic models embedded in these codes vary widely in their abilities to capture precast joint behavior.

2) Relationships need to be developed by which hysteretic parameter coefficients can be determined a priori given only geometric and material properties for a proposed joint detail. This technique is reaching maturity at NIST in studies of RC bridge columns and cast-in-place shear wall structures [Stone and Taylor, 1993; Phan, Todd, and Lew, 1993].

At NIST the authors have adopted a 5-parameter hysteretic model which includes strength degradation, stiffness degradation, pinching, slip initiation, and slip length. This model has been embedded in IDARC 3.3 [Kunnath, et.al, 1993] as well as in the NIST graphics-based 
system identification package NIDENT 5.0 [Stone and Taylor, 1993]. A sample of the capabilities of this model is shown in Figs. A1 and A2 in which the load-displacement history of NIST specimen A-P-Z4 has been analytically generated given only the laboratory displacements as input. Other models, including differential equation based "smooth" models [e.g. El-Borgi et.al., 1992] could have been used. However, from the viewpoint of computational efficiency the 5-parameter linear model is superior and the loss in accuracy is negligible.

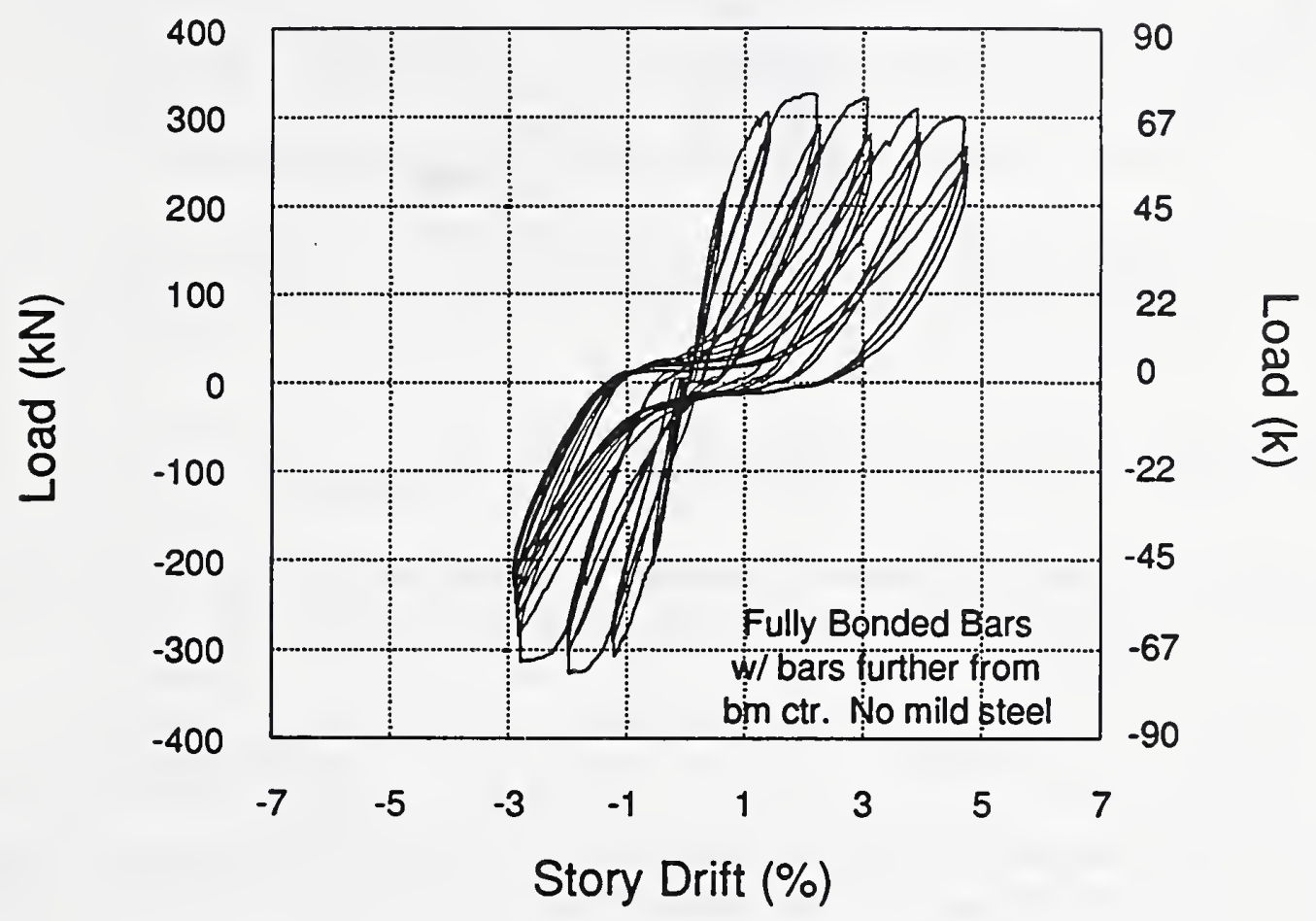

Figure 16. Experimental Hysteresis Curves for NIST Specimen A-P-Z4. 


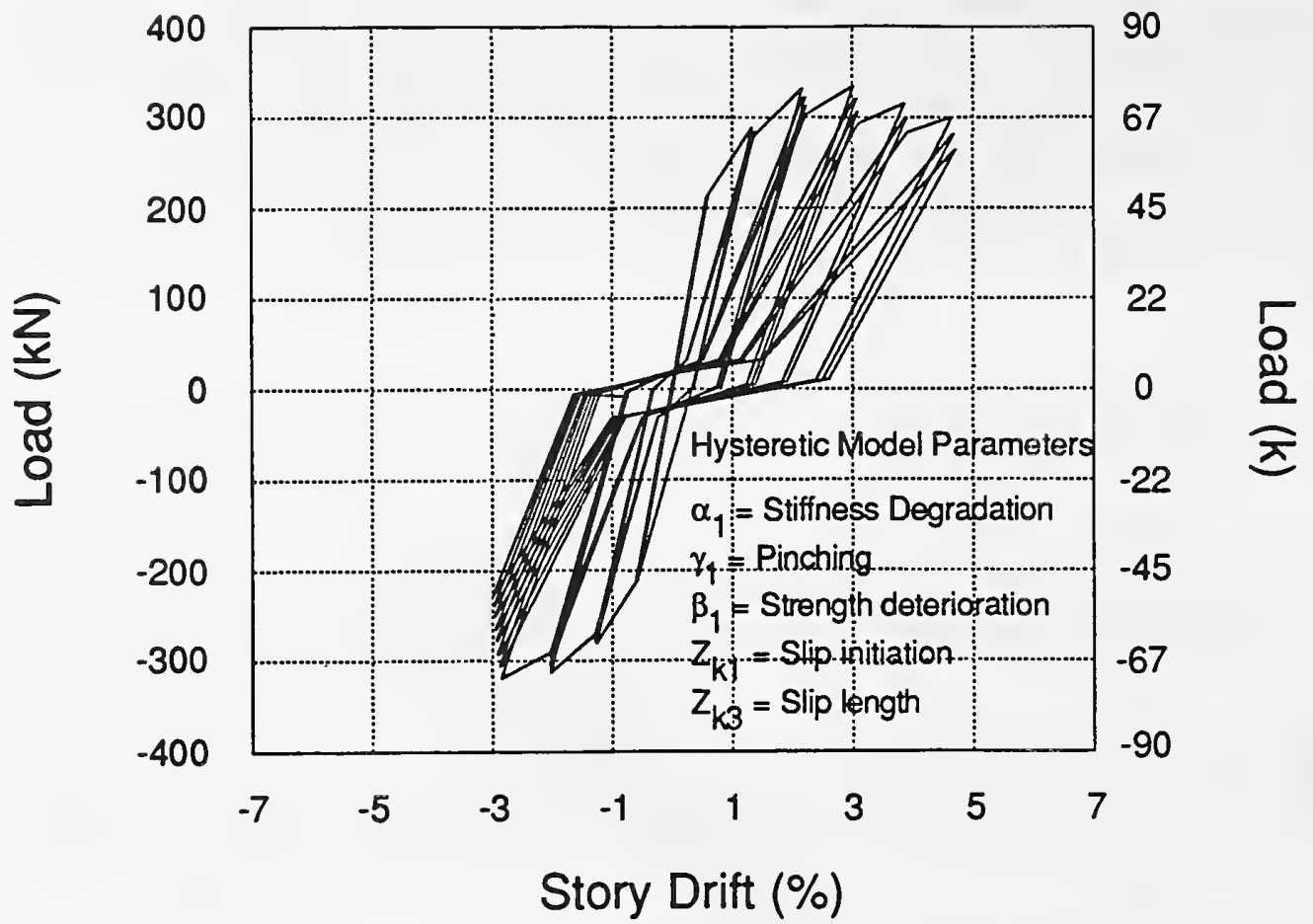

Figure 17. Predicted Hysteresis Curves Produced Using NIDENT 5.0 System Identification and IDARC 3.3 Inelastic Solution

Upon completion of laboratory parametric tests of the most promising of the hybrid connection designs, refinement of analytical methods for modeling the hysteretic behavior observed in the laboratory tests will be carried out. This work will be extended towards the development of a simplified (static equivalent, elastic) design criterion for precast moment resisting frames as follows:

1. A broad range of moment resisting 2-D precast frames will be designed which utilize the various precast joint details previously described (and for which hysteretic parameter coefficients have already been determined via system identification at NIST). These frames will be chosen in consultation with industry as being representative of the majority of commercial building designs that might be contemplated for this type of construction.

2. For each matrix of geometric (story height, number of stories, bay width, number of bays, beam and column dimensions and reinforcement details) and material (concrete and steel strengths and stress strain relations) characteristics corresponding to each type of precast system, computer models will be subjected to a series of design earthquake suites (5-10 records each) for varying epicentral distances and magnitudes. The inelastic transient behavior will be determined on the basis of interstory drift vs. time and the peak interstory drift for each run. Each analysis set will be repeated to represent the following conditions: 

A. Zone 4 events (typical of California)
B. Zone 2 events (typical of eastern U.S.)
C. UBC/SEAOC soil types S1 - S4

An automated graphics-based program, EARTHGEN 1.0, for generation of bedrock earthquake ensembles has already been developed at NIST [Taylor and Stone, 1991] such that the massive number of analyses can be handled with relatively little effort. Historic records, scaled to match target response spectra generated via existing attenuation relationships [e.g. Idriss, 1993] will be used for Zone 4 analyses; synthetic generation techniques will be used for Zone 2. The output of EARTHGEN is compatible for direct input into ISDP the NIST Integrated Seismic Design Procedure [Stone and Taylor, 1993], an automated inelastic analysis package which accounts for soil type.

3. Elastic analyses will be conducted corresponding to Step 2 above using UBC/SEAOC simplified lateral load design criteria and determine peak interstory drifts.

4. On the basis of Steps 2 and 3 above, response modification factors $\left(R_{w}\right)$ as a function of earthquake energy content (magnitude, distance) will be determined.

5. Based on Step 4, statistical analyses (step wise, linear regression) will be conducted to develop closed form equations defining $R_{w}$ as a function of earthquake magnitude, epicentral distance, soil type, and seismic zone. Sensitivity analyses will then be used to determine the conditions in which a single value for $\mathrm{R}_{\mathrm{w}}$ is appropriate.

In Step 5, at a certain energy content (as manifested by combinations of larger magnitude and shorter epicentral distances) unacceptable structural behavior may be exhibited, either in the form of excessive maximum drift, excessive residual drift, or high damage levels that might affect structural integrity. An initial performance-based design criterion, in which there is a sliding scale of permissible damage (or drift) directly tied to energy content, has been developed at NIST [Stone and Taylor, 1993]. What remains is for code-writing bodies to refine such an approach in parallel with (and eventually in lieu of) the "maximum credible earthquake." This would permit a rational link between simplified design procedures and with time history analyses, which presently does not exist. 


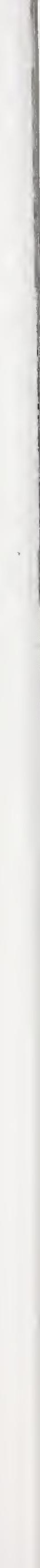




\section{ACKNOWLEDGEMENTS}

The support of Mr. Frank Rankin, Mr. Max Peltz, Mr. Jim Little, and Mr. Erik Anderson of the Structures Division laboratory staff is gratefully acknowledged. Special thanks are extended to Mr. Dean Stephan, Mr. Dave Seagren, and Dr. John Stanton for their invaluable support and advice in the Phase IV tests.

The authors would also like to extend their thanks for the technical support from the following individuals: Dr. Robert Englekirk, Dr. Cathy French, Dr. S. K. Ghosh, Mr. Jacob Grossman, Dr. Grant Halverson, Mr. Dan Jenny, Mr. Paul Johal, Mr. Bob Mast, Ms. Suzanne Nakaki, Mr. Courtney Phillips, Dr. Nigel Priestley, Mr. Barry Schindler, and Mr. Norm Scott. The support and/or donations of materials from Charles Pankow Builders, Ltd., the Concrete Research and Education Foundation, Dywidag Systems International, and Allied Fibers are gratefully acknowledged. 


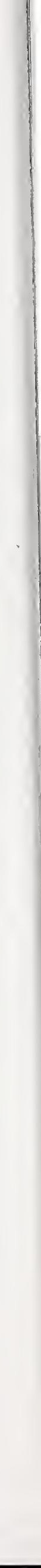




\section{REFERENCES}

Allahabadi, Rakesh (1987), "Drain-2DX, Seismic Response and Damage Assessment for 2D Structures," Department of Civil Engineering, University of California, Berkeley, March 1987.

Cheok, G. and Lew, H. S. (1990), "Performance of 1/3-Scale Model Precast Concrete Beam-Column Connections Subjected to Cyclic Inelastic Loads," NISTIR 4433, NIST, Gaithersburg, MD, Oct. 1990.

Cheok, G. and Lew, H. S. (1991), "Performance of 1/3-Scale Model Precast Concrete Beam-Column Connections Subjected to Cyclic Inelastic Loads - Report No. 2," NISTIR 4589, NIST, Gaithersburg, MD, Jun. 1991.

Cheok, G., Stone, W., and Lew, H. S. (1992), "Partially Prestressed and Debonded Precast Concrete BeamColumn Joints", Proceedings of the $3^{\text {rd }}$ Meeting of the U.S. - Japan Joint Technology Coordinating Committee on Precast Seismic Structures Systems, Nov. 1992.

Cheok, G. and Lew, H. S. (1993), "Model Precast Concrete Beam-to-Column Connections Subject to Cyclic Loading," paper submitted to PCI Journal for publication.

El-Borgi, S., Stone, W.C., White, R.N., and Gergely, P. (1992), "Analytical Study on Seismic Behavior of Lightly Reinforced Concrete Frame Buildings," NIST Project 50SBNB1C6543, Report \#3, School of Civil and Environmental Engineering, Cornell University, Ithaca, NY 14853, September 15, 1992, 172pp.

French, C., Amu, O., Tarzikhan, C. (1989), "Connections Between Precast Elements - Failure Within Connection Region," ASCE Structural Journal, New York, NY, Feb. 1989, pp. 3171 -3192.

Hart, G.C. (1992), "Design Criteria for Precast Concrete Structures: Foundation of a New Direction," Report on the Third U.S. PRESSS Coordinating Meeting, Report No. PRESSS-92/02, August, 1992, Dept. of Applied Mechanics \& Engineering Sciences, UCSD, La Jolla, CA, 28pp.

Idriss, L.M. (1993), "Procedures for Selecting Earthquake Ground Motions at Rock Sites," Report to the Structures Division of the Building and Fire Research Laboratory, NIST, Gaithersburg, MD 20899, February 1993.

International Conference of Building Officials (1985, 1988), Uniform Building Code, Whittier, CA, 1985 \& 1988.

Park, YJ., Reinhorn, A.M., and Kunnath, S.K. (1987), "IDARC: Inelastic Damage Analysis of Reinforced Concrete Frame-Shearwall Structures, (1987), ${ }^{n}$ Department of Civil Engineering, State University of New York at Buffalo, Buffalo, NY 14260, Technical Report NCEER-87-0008, July 20, 1987.

Phan, L.T., Todd, D.R., and Lew, H.S. (1993), "Strengthening Methodology for Lightly Reinforced Concrete Frames-I," NISTIR-5128, National Institute of Standards and Technology, Gaithersburg, MD, February 1993, $100 \mathrm{pp}$.

Priestley, MJ.N, Ed. (1992), "Report on the Third U.S. PRESSS Coordinating Meeting," Report No. PRESSS92/02, Dept. of Applied Mechanics \& Engineering Sciences, UCSD, La Jolla, CA, August, 1992.

Priestley, M. J. N. and Tao, J. R. (1993), "Seismic Response of Precast Prestressed Concrete Frames with Partially Debonded Tendons," PCI Journal, Vol. 38, No. 1, Jan/Feb 1993, pp. 58-69.

Stone, W.C, and Taylor, A.W. (1993), "Seismic Performance of Circular Bridge Columns Designed in Accordance With AASHTO/CALTRANS Standards," BSS-170, National Institute of Standards and Technology, Gaithersburg, MD, February 1993, 125pp.

Stone, W.C., and Taylor, A. (1992), "A Predictive Model for Hysteretic Failure Parameters," Proceedings of the 10th World Conference on Earthquake Engineering, July 19-24, 1992, Madrid, Spain, A.A. Balkema, Rotterdam, 1992, pp. 2575-2580.

Taylor, A.W., and Stone, W.C. (1991), "Selecting Bedrock Motions for the Seismic Design of Bridges," U.S.Japan Workshop on Earthquake Protective Systems for Bridges, National Center for Earthquake Engineering Research (NCEER), State University of New York, Buffalo, September 4-5, 1991. 


\section{Appendix A* \\ Development of Relationships for Acceptable Damage}

In this section relationships are proposed for acceptable levels of seismic damage to spiral reinforced bridge piers. In this study damage is quantified in terms of the damage index, and acceptable values of the damage index are expressed in terms of earthquake magnitude, distance of the structure from the causative fault, and the importance of the structure.

Acceptable levels of structural performance (e.g., minimum strength, allowable deflections) are normally determined by code writing organizations, and local, state and national government agencies. However, no guidelines for acceptable levels of seismic damage currently exist. Because the notion of employing a "damage index" to gage the seismic performance of reinforced concrete structures is relatively new, code writing bodies have not yet addressed the issue of determining an "acceptable" damage index for a given structure subjected to a given seismic event. Therefore, a proposed model for acceptable damage level was derived in this study, and is described below. While the model was developed specifically for spiralreinforced concrete bridge piers, with minor modifications the model could be applied to other types of reinforced concrete members and structures.

The level of seismic damage deemed "acceptable" for a given structure is mainly a function of two conditions: the severity of the seismic event, and the importance of the structure. In turn, the severity of the seismic event depends on a number of subsidiary factors, including the magnitude of the event, the distance of the causative fault from the structure, and the ground motion attenuation characteristics of the local geology. Likewise, the importance of the structure depends on several subsidiary factors, such as the threat to life-safety posed by the structure, the role of the structure in maintaining essential lifeline services (transportation, communication, utilities delivery, medical care, and governance) following a major earthquake, and the potential cost of repair or replacement of the structure.

Thus, many factors figure into the determination of an acceptable level of damage for a specific structure at a specific location subjected to a specific seismic event. For example, extensive damage of an unimportant and inexpensive structure in a minor seismic event might be tolerated, but a highly important structure might be required to remain fully operational following a severe earthquake. Along these lines, a number of guiding principles can be stated which shape the development of a model of acceptable damage. First, regardless of the characteristics of the seismic event or the importance of the structure, total collapse of the structure

\footnotetext{
* Extracted from Stone and Taylor 1993
} 
must be avoided, as total collapse would likely result in loss of life. Second, for small events at large distances from causative faults the damage suffered by any structure should be minor. Depending on the importance of the structure, this minor level of damage should lie somewhere between the state of no perceptible damage and the state of first yield. Third, for very large, extraordinary, seismic events (on the order of magnitude 8) extensive damage is unavoidable even at moderate distances from the causative fault (say $40 \mathrm{~km}$ ). Therefore damage indices approaching (but less than) the failure damage state must be allowed in some cases. Finally, allowable damage levels should in general be lower for important structures than for unimportant structures.

Using the guiding principles outlined above, matrices of acceptable damage indices could be constructed, which are functions of earthquake magnitude, distance to fault and structural importance. Although the precise level of acceptable damage at a given magnitude, distance and structural importance level is somewhat open to interpretation, the approximate levels of acceptable damage are generally evident. In this study, three damage index thresholds have been defined: yield, ultimate, and failure. Acceptable damage index matrices are constructed in terms of those threshold values.

An example of a matrix of acceptable damage indices is illustrated by the bar chart in figure A1. The proposed values shown are for bridge piers which are deemed moderately important to seismic lifelines, that is, for piers in bridges which are judged to have a secondary role in sustaining transportation routes and emergency services following an earthquake. Notice that for earthquakes near magnitude $8.0 \mathrm{a}$ high level of allowable damage is proposed for all distances up to about $50 \mathrm{~km}$. This reflects the difficulty and impracticality of limiting damage of moderately important bridges subject to massive, extremely rare events, even at considerable distances from causative faults. Similarly, a fairly high level of damage is allowed for moderate magnitude earthquakes at small distances, up to about $30 \mathrm{~km}$. Very low levels of damage are permitted for low magnitude earthquakes at moderate-tolarge distances. 


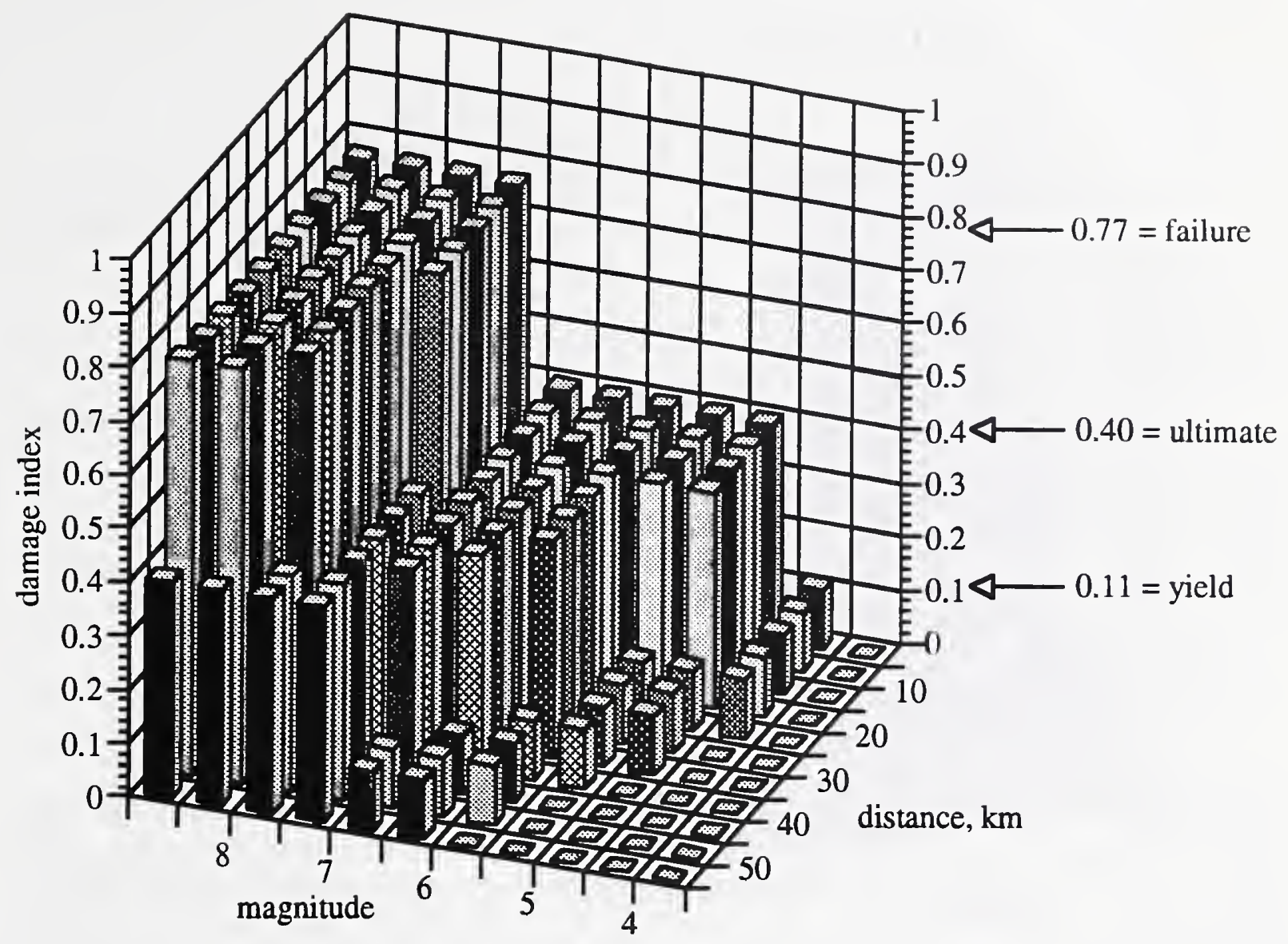

Figure A1. Estimated acceptable damage indices, as functions of magnitude and distance, for bridge piers deemed moderately important to seismic lifelines.

Figure A2 shows a matrix of proposed allowable damage indices for piers in bridges which are highly important to seismic lifelines. High levels of damage are acceptable only for very large events at small distances, and the allowable damage index decreases rapidly as distance increases and magnitude decreases. This would permit most important lifeline bridges - except those very close to the causative fault - to remain in limited operation following a major earthquake. At moderateto-small magnitudes and moderate-to-large distances little or no damage is allowed, since under those conditions important lifeline bridges should remain completely serviceable. 


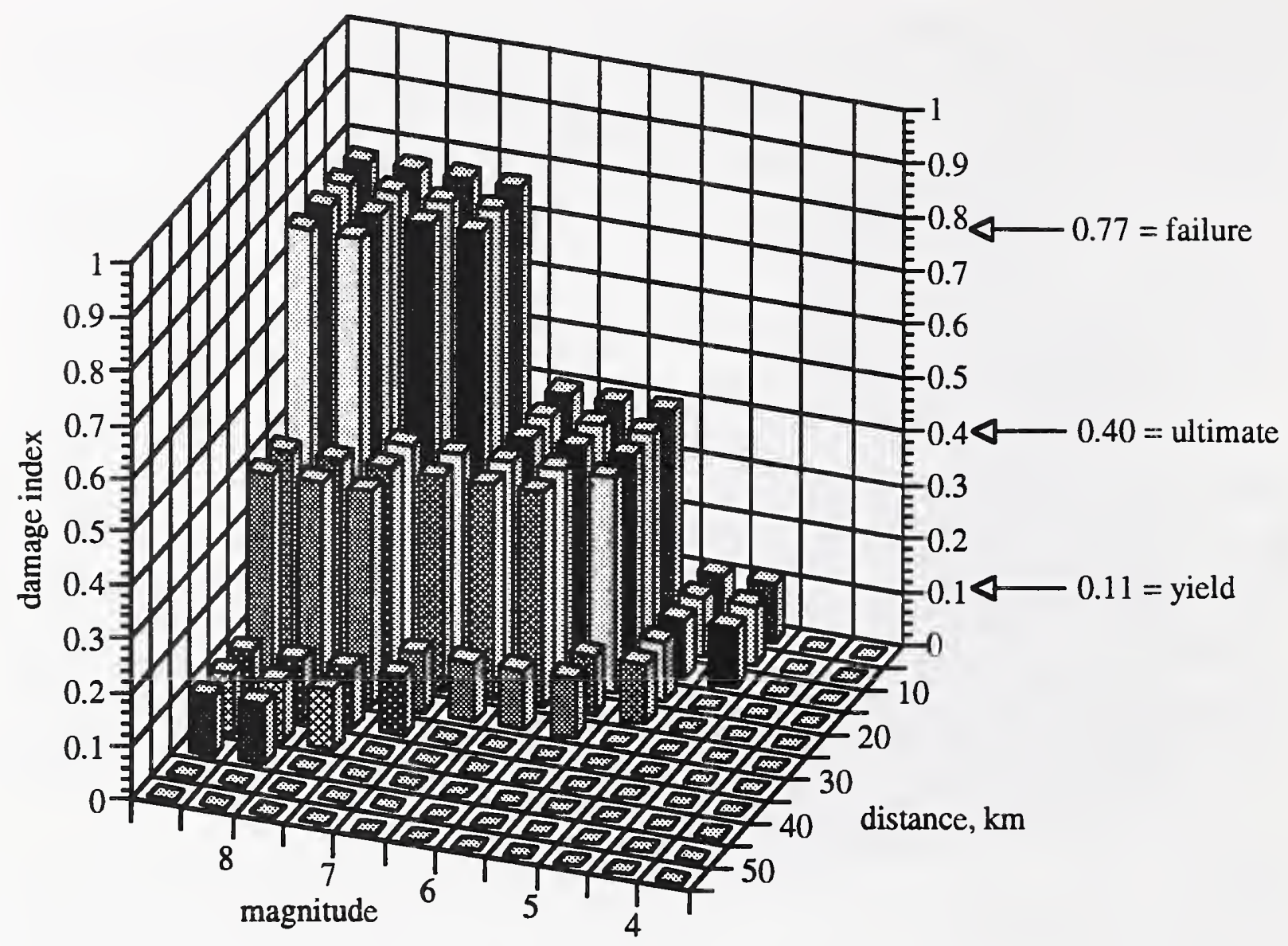

Figure A2. Estimated acceptable damage indices, as functions of magnitude and distance, for bridge piers deemed highly important to seismic lifelines.

The process outlined above can be extended another step by fitting smooth, threedimensional surfaces to the discrete values shown in the bar charts of figures Al and A2. In this way acceptable damage levels for moderately important and highly important bridge piers can be expressed as simple, continuous functions of magnitude and distance. Continuous functions have the advantage of being easily usable by design engineers, and, unlike tables of discrete values, continuous functions provide unambiguous values of acceptable damage at any magnitude and distance. A simple surface with a shape appropriate to the data of figures A1 and A2 is a hyperbolic trumpet, which has an equation of the form 


$$
\text { D. I. }=\frac{1}{\frac{\mathrm{D}^{2}}{\mathrm{a}}+\frac{(9-\mathrm{M})^{2}}{\mathrm{~b}}}-\mathrm{c}
$$

$\begin{array}{lll}\text { where } & \text { D.I. }= & \text { damage index } \\ \mathrm{D}= & \text { distance, } \mathrm{km} \\ \mathrm{M}= & \text { earthquake moment magnitude } \\ \mathrm{a}, \mathrm{b}, \mathrm{c}= & \text { coefficients }\end{array}$

and

$$
\begin{aligned}
& 0 \leq \text { D.I. } \leq 0.77 \\
& 5 \leq \mathrm{D} \leq 50 \\
& 5.0 \leq \mathrm{M} \leq 8.0
\end{aligned}
$$

The valid range of the surface is limited by the three conditions on damage index, distance, and magnitude, as shown above. The first condition reflects the fact that damage indices greater than the failure damage index, determined in this study as 0.77 for spirally reinforced bridge piers, are not possible. The second and third conditions are imposed by limitations on the ranges of distance and magnitude investigated in this study.

Figures A3 and A4 show surfaces which, in general, fit conservatively (that is, generally provide a lower bound to) the bar graphs of figures $\mathrm{Al}$ and $\mathrm{A} 2$. These surfaces have equations of the form shown above. The equations of the curves in figures $\mathrm{A} 3$ and $\mathrm{A} 4$ were found by selecting three mathematical control points for each curve, which in turn were used to solve for the coefficients $a, b$ and $c$. The control points used in this study are shown in table Al below. Although some of the control point values are outside the normal ranges considered in design, they do serve to mathematically constrain the smoothed curves of figures $\mathrm{A} 3$ and $\mathrm{A} 4$ so that they generally form lower bounds to the bar graphs of figures A1 and A2, over practical ranges of magnitude and distance $(5 \mathrm{~km} \leq$ distance $\leq 50 \mathrm{~km}$ and $5.0 \leq$ magnitude $\leq 8.0$ ). 
Table A1. Control points used to solve for curves of figures A3 and A4

\begin{tabular}{|l|c|c|c|}
\cline { 2 - 4 } \multicolumn{1}{c|}{} & Magnitude & Distance & Damage Index \\
\hline \multicolumn{3}{|c|}{ Structures of Moderate Importance to Seismic Lifelines (figure A1) } \\
\hline Control Point 1 & 6.5 & 0 & 0.77 \\
\hline Control Point 2 & 9.0 & 65 & 0.40 \\
\hline Control Point 3 & 9.0 & 50 & 0.77 \\
\hline \multicolumn{1}{|c|}{ Structures of High Importance to Seismic Lifelines (figure A2) } \\
\hline Control Point 1 & 7.0 & 0 & 0.4 \\
\hline Control Point 2 & 9.0 & 50 & 0.0 \\
\hline Control Point 3 & 4.0 & 0 & 0.0 \\
\hline
\end{tabular}

The equation of the surface in figure $\mathrm{A} 3$, for moderately important bridge piers, is

$$
\text { D.I. }=\frac{1}{\frac{D^{2}}{2300}+\frac{(9-M)^{2}}{5.7}}-0.14
$$

where

$$
\begin{array}{ll}
\text { D.I. }= & \text { damage index } \\
\mathrm{D}= & \text { distance, } \mathrm{km} \\
\mathrm{M}= & \text { earthquake moment magnitude } \\
\mathrm{a}, \mathrm{b}, \mathrm{c}= & \text { coefficients }
\end{array}
$$

and

$$
\begin{aligned}
& 0 \leq \mathrm{D} . \mathrm{I} . \leq 0.77 \\
& 5 \leq \mathrm{D} \leq 50 \\
& 5.0 \leq \mathrm{M} \leq 8.0
\end{aligned}
$$




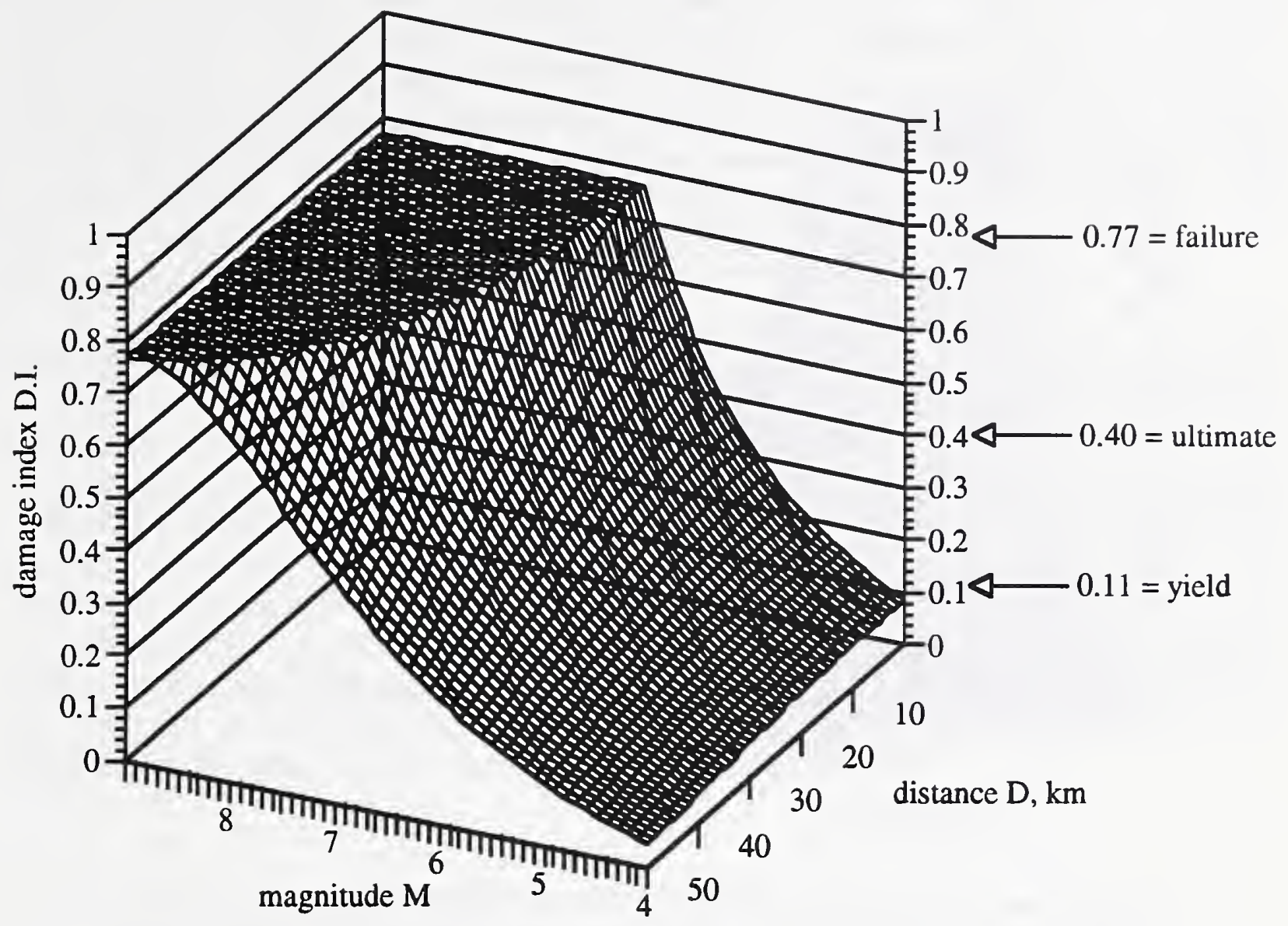

Figure A3. Proposed envelope for acceptable damage index, as a function of magnitude and distance, for bridge piers deemed moderately important to seismic lifelines.

The equation for the surface in figure A4, for highly important bridge piers, is

$$
\text { D.I. }=\frac{1}{\frac{D^{2}}{190}+\frac{(9-M)^{2}}{1.9}}-0.08
$$

$$
\begin{aligned}
& 0 \leq \text { D.I. } \leq 0.77 \\
& 5 \leq \mathrm{D} \leq 50 \\
& 5.0 \leq \mathrm{M} \leq 8.0
\end{aligned}
$$




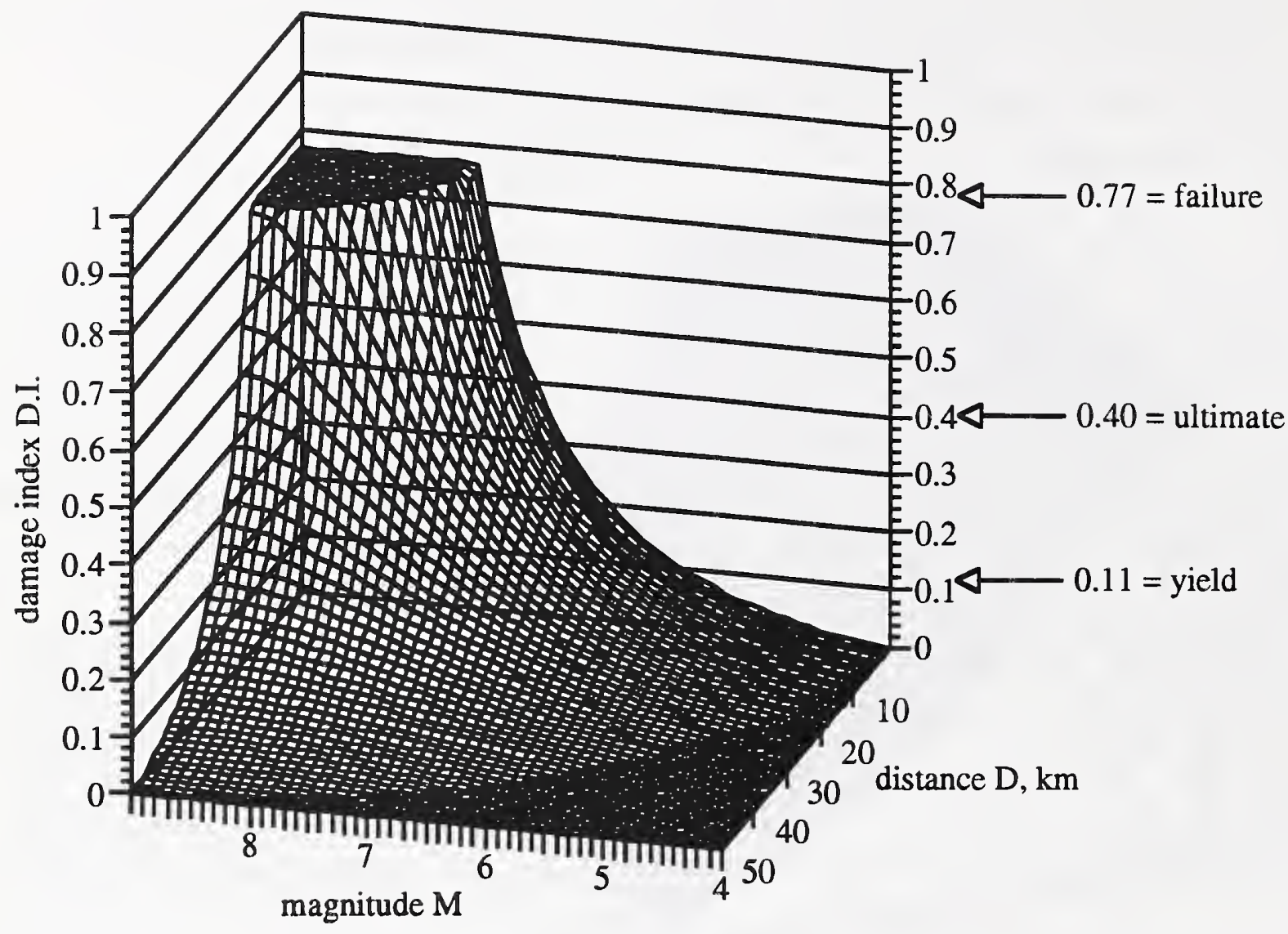

Figure A4. Proposed envelope for acceptable damage index, as a function of magnitude and distance, for bridge piers deemed highly important to seismic lifelines.

Further refinement of these acceptable damage level surfaces is possible, and other surfaces could be constructed for other types of members and structures and other levels of structural importance. The presentation here of the steps followed in deriving these surfaces is intended as a demonstration of a rational procedure. Such a procedure could be followed by code-writing bodies, and by government agencies, to derive similar curves for the types of structures under their jurisdiction.

\section{Discussion: Acceptable Damage Limits}

The acceptable damage model developed above presents an initial attempt by the authors to address the complex, socio-economic-technological topic that is summarized by the question: "What cost are we willing to pay in order for a particular bridge to survive a given earthquake?" The authors have proposed a non-linear scale which relates allowable damage level to earthquake intensity and 
structural importance. The criteria were developed, somewhat subjectively, by considering limiting cases in a three-dimensional space defined by allowable damage, distance from the earthquake epicenter, and earthquake magnitude. From these discrete values parametric equations were developed to model the threedimensional surfaces of acceptable damage. Equations for two classes of bridges were presented: bridges deemed moderately important to seismic lifelines, and bridges deemed highly important to seismic lifelines. This was largely done in an effort to maintain consistency with existing design procedures, which also recognize two levels of importance.

Refinement of the acceptable damage models beyond the ones presented by the authors will necessarily involve probabilistic analyses on the likelihood of a particular earthquake occurring during the useful lifetime of a bridge, as well as the estimation of the cost to society of repair/retrofit/replacement of the bridge following a particular earthquake. While these tasks are well-defined, they are beyond the scope of the present study. The important distinctions between this approach and the approach presently employed by the model code agencies are that a) the concept of acceptable damage, as a calculable quantity, replaces ambiguous safety factors and base shear coefficients and b) the acceptable performance is tied specifically to two engineering quantities: the earthquake magnitude and the distance of the construction site from the earthquake source. 
APPENDIX B: ORGAINIZATIONAL CHART

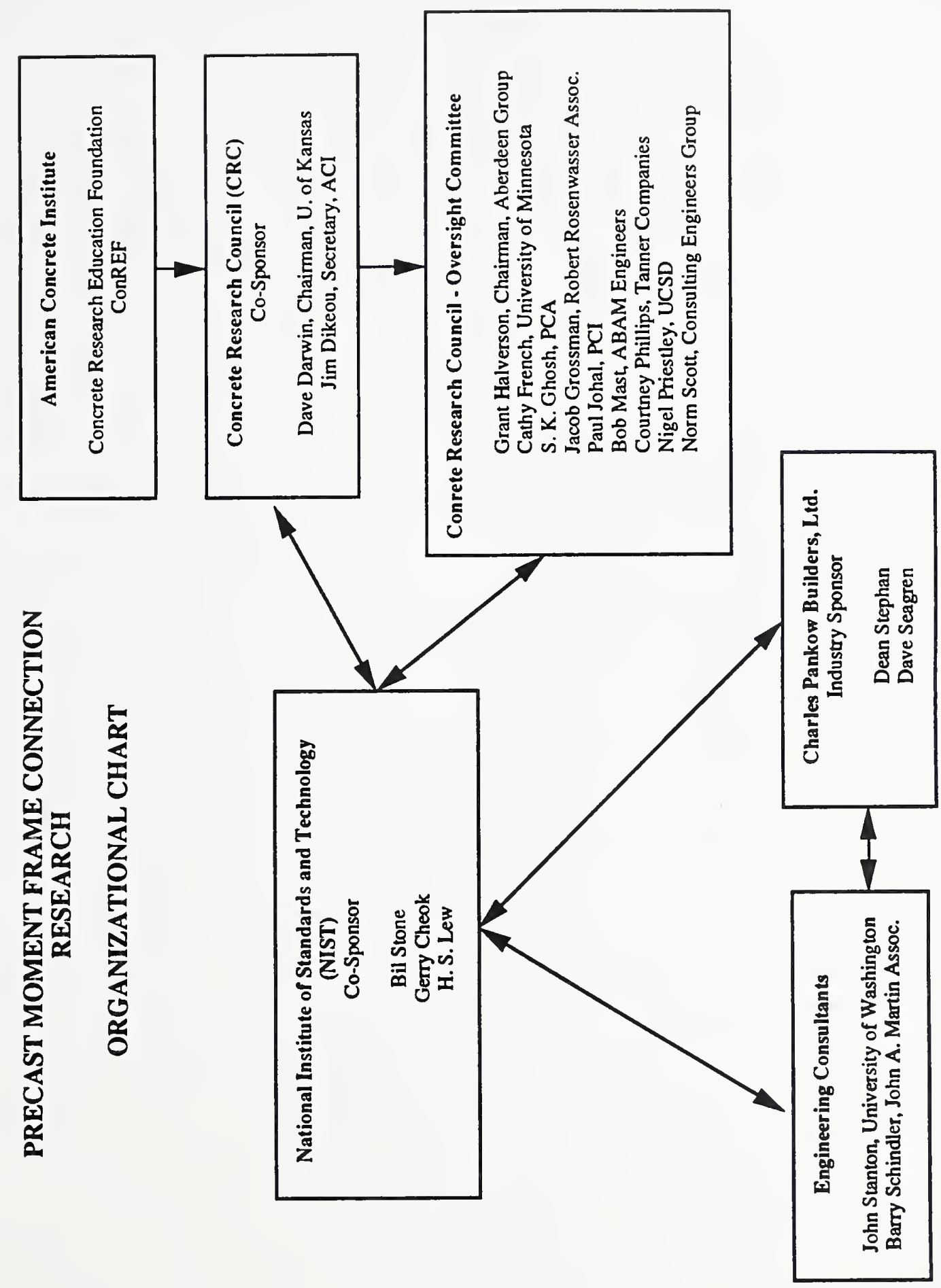



